\title{
Contribuição à Previsão da Vida Útil de Estruturas de Concreto
}

\author{
Denise Carpena Coitinho Dal Molin \\ Angela Borges Masuero \\ Jairo José de Oliveira Andrade \\ Edna Possan \\ João Ricardo Masuero \\ Marina Martins Mennucci
}

\section{Introdução}

O desenvolvimento de novas tecnologias, processos construtivos e materiais de construção tem fomentado a construção de edificaçôes cada vez mais esbeltas e econômicas. Porém, a carência de mão de obra especializada, a alta competitividade do setor e/ou a busca por maiores lucros por meio da redução dos custos de produção têm interferido negativamente na qualidade das habitaçóes produzidas no Brasil nos últimos anos.

É comum encontrar construçôes com níveis de degradação superior aos desejados com problemas relacionados à qualidade e à durabilidade devido a falhas de execução e ao aparecimento de manifestaçóes patológicas, o que afeta a estética, a segurança, a usabilidade e a vida útil das edificações.

Visando à melhoria da qualidade dos produtos da indústria da construção como um todo, entrou em vigor, em 2013, a "Norma de Desempenho" (ABNT NBR 15575, 2013) que estabelece parâmetros mínimos de desempenho ${ }^{1}$ para os sistemas construtivos, bem como para as edificaçôes habitacionais, de modo a atender as necessidades e exigências dos usuários ao longo do ciclo de vida da habitação, atuando de forma complementar com o conjunto de normas prescritivas da ABNT vigentes e já difundidas na comunidade da construção.

1. Comportamento em uso. 
Para cada um dos sistemas ${ }^{2}$ que compóe a edificação, o documento insere 12 critérios de desempenho ${ }^{3}$, sendo um deles o de "durabilidade", em atendimento aos requisitos ${ }^{4}$ de segurança e qualidade.

A durabilidade de cada sistema que compóe a edificação pode ser mensurada por meio da vida útil de projeto (VUP), que é o período de tempo compreendido entre o início de operação e uso de uma edificação até o momento em que o seu desempenho deixa de atender às exigências do usuário, sendo diretamente influenciada pelas atividades de manutenção e reparo e pelo ambiente de exposição. A NBR 15575 (2013) resume vida útil como "uma medida temporal da durabilidade de um edifício ou de suas partes".

Cabe destacar que a maioria dos estudos de previsão de vida útil de um projeto é voltada ao sistema "estruturas", visto ele ser considerado o principal sistema da edificação, por conta da exigência normativa de maior tempo de vida útil (VUP mínima de 50 anos) e pela eventual inviabilidade da substituição, alteração ou retirada de qualquer elemento ou componente que o constitua devido aos custos elevados, à dificuldade técnico-executiva e aos riscos associados.

Deve-se considerar que a norma de desempenho NBR 15575 (2013) não exclui a validade das demais normas existentes, como o caso da NBR 6118 (ABNT, 2014) e da NBR 12655 (ABNT, 2015), que apesar de especificarem valores de cobrimento da armadura, relaçóes água/cimento máximas e resistências mínimas em função da agressividade ambiental, não apresentam elementos necessários para estimar a vida útil das estruturas. Da mesma forma, existem diversas normas brasileiras de ensaios de durabilidade (ABNT NBR 9779:2012; ABNT NBR 10787:2011; ABNT NBR 15577-1:2008, entre

2. Conjunto de componentes e elementos com função definida (exemplos: o "sistema estrutural” - com a função de dar suporte à edificação, é formado pelo conjunto de elementos estruturais "vigas, lajes e pilares" - produzidos com o componente "concreto armado". Já o sistema "vedações verticais" - com a função de proteger e vedar a edificação, é formado pelos elementos "paredes de alvenaria" por sua vez produzido com os componentes "argamassa" e "blocos cerâmicos ou de concreto").

3. Critérios de desempenho são especificaçóes quantitativas dos requisitos de desempenho (qualitativos), expressos em termos de quantidades mensuráveis, a fim de que possam ser objetivamente determinados (NBR 15575-1:2013).

4. Requisitos de desempenho são condiçóes que expressam qualitativamente os atributos que a edificação e suas partes devem possuir, a fim de que possam satisfazer às exigências do usuário (NBR 15575-1:2013). 
outras), bastante apropriadas para comparar diferentes materiais e sistemas construtivos, porém não fornecem estimativas de vida útil das estruturas.

Nesse contexto, vários modelos de previsão de vida útil, que possam descrever adequadamente o processo de degradação das estruturas de concreto armado ao longo do tempo, vêm sendo desenvolvidos. Muitos destes modelos abordam a corrosão das armaduras, que é a manifestação patológica preponderante nas estruturas de concreto, cujos mesmos tentam modelar a penetração dos principais agentes agressivos responsáveis pela despassivação da armadura: os íons cloreto e o dióxido de carbono (CO2) (HAMADA, 1969; HO e LEWIS, 1987, PAPADAKIS et al., 1991a, PAPADAKIS et al., 1991b; JIANG et al., 2000; HYVERT, 2009, TUUTTI, 1982; UJI et al., 1990; MANGAT et al., 1994; MEJLBRO, 1996; ANDRADE, 2001; entre outros). Como a maioria dos modelos de previsão de vida útil existentes na bibliografia são bastante complexos, este capítulo tem como objetivo apresentar modelos de previsão de vida útil a serem adotados para avaliação de sistemas construtivos em concreto armado (modelos que sejam de fácil aplicação, a partir de dados de entrada possíveis de serem determinados sem ensaios adicionais em laboratório), bem como medir as variabilidades existentes nos processos de produção do concreto armado e nos ambientes, de forma a utilizar em modelos de previsão de cunho probabilísticos. Conhecer estas variabilidades e propor formas de minimizá-las é de suma importância para que se possa garantir uma VUP mínima para uma estrutura construída em concreto.

\section{Normalização Referente à Durabilidade e Previsão de Vida Útil de Sistemas Estruturais em Concreto}

A crescente preocupação com a durabilidade e vida útil das edificaçôes em concreto armado instigou a comunidade técnico-científica a desenvolver soluçôes para minimizar os danos decorrentes do processo de degradação. Nesse sentido, organizaçóes como a Federação Internacional do Concreto Estrutural - fib (Fédération Internationale Du Béton) - e o Instituto Americano do Concreto - ACI (American Concrete Institute) - por meio de seus comitês técnicos e grupos de trabalhos, têm desenvolvido relatórios e práticas recomendadas com o intuito de resolver problemas dessa natureza.

5. Organização internacional criada em 1998, a partir da fusão de duas entidades independentes, que existiam desde 1952: o CEB (Comité Euro-International du Béton) e a FIP (Fédération Internationale de la Précontrainte). 
Primeiramente, essas instituiçóes desenvolveram roteiros relacionados à durabilidade do concreto, destacando-se o ACI 201 (1992) - "Guide to Durable Concrete" -, o CEB 183 (1992) - "Durable concrete structures" e o CEB 238 (1997) - "New approach to durability design: an example for carbonation induced corrosion".

Tanto a fib como o ACI, por meio de seus comitês, deram início aos estudos relacionados à previsão de vida útil, englobando também a análise do ciclo de vida (ACV). Nos boletins publicados, apresenta-se uma visão holística, que abrange desde aspectos relacionados à concepção, projeto, execução, utilização, manutenção, adequação, até fatores de ordem econômica. Dentre as publicaçóes da área, destacam-se o ACI 365 (2000) e o fib 34 (2006).

O ACI 365 (2000), intitulado "Service Life Prediction: state-of-the-art report", apresenta informaçôes orientadas à predição de vida útil de estruturas de concreto armado, tanto novas como existentes, oferecendo dados sobre os fatores que controlam a vida útil das estruturas, metodologias para a avaliação da condição de estruturas existentes e técnicas matemáticas voltadas à predição de vida útil. O relatório também discute alguns aspectos econômicos concernentes à vida útil das estruturas de concreto, incluindo a análise do custo do ciclo de vida.

O "Model Code for Service Life Design" - fib 34 (2006) foi instaurado com o objetivo de identificar modelos consensuais relacionados à durabilidade e de preparar uma estrutura física voltada à normalização do projeto baseada na aproximação de desempenho. Destina-se à previsão de vida útil de estruturas de concreto simples, armado e protendido, com foco especial nas prescriçóes de projeto que tem como objetivo controlar os efeitos adversos da degradação, considerando as açôes ambientais que conduzem à deterioraçáo do aço imerso no concreto. A metodologia descrita nesse documento também pode ser aplicada para a avaliação da vida útil de estruturas existentes.

Nesse sentido, destacam-se ainda as publicações ISO 15686 e EUROCODE 2. A norma ISO 15686 (2011) "Buildings and constructed assets: Service life planning" e complementares (de 1 a 11) destinam-se ao estudo da durabilidade, abrangendo a vida útil, o ciclo de vida e o impacto ambiental das edificaçôes. O EUROCODE 2 (2004) "Design of concrete structures" e suas partes 1, 2 e 3, em relação à publicação anterior de 1992, inserem uma nova abordagem para o projeto de estruturas de concreto, trazendo critérios baseados em conceitos probabilísticos. A nova versão da norma ISO 13823 (2008) “Generalprinciples 
on the design of structures for durability" enfatiza que é necessário garantir a confiabilidade do desempenho de uma estrutura desde a concepção até o final da sua vida útil, recomendando que procedimentos probabilísticos sejam empregados. Nessa mesma linha conceitual, cita-se ainda o fib 53 (2010) "Design of durable concrete structures".

Com o intuito de criar um código do concreto e promover a cooperação e o entendimento entre as naçóes integrantes do continente Asiático e da Região do Pacífico, foi desenvolvido pelo ICCMC 6 , em parceria com $\mathrm{JCI}^{7}$, o "Asian Concrete Model Code" - ACMC (2006). O objetivo principal desse código é elevar o padrão de desempenho estrutural e de segurança das estruturas de concreto frente às condiçóes sociais e ambientais, coletando padróes e práticas utilizadas em cada país, a fim de desenvolver um modelo comum para todo o território Asiático. O ACMC contempla o projeto, a construção e a manutenção, os quais podem ser convertidos e adaptados dentro dos diferentes contextos.

$\mathrm{Na}$ África também está em desenvolvimento o Código Africano do Concreto, o ACC (African Concrete Code), que tem por objetivo atuar como um guia para o projeto de estruturas de concreto duráveis, úteis, econômicas e seguras, em harmonia com o ambiente natural e social do continente, servindo como ferramenta para facilitar e acelerar o desenvolvimento econômico e a transferência de tecnologia, no campo da engenharia do concreto, entre a região Africana e a Comunidade Internacional. Contando com a participação de especialistas da Europa, da Ásia, dos Estados Unidos e da África, um simpósio realizado em $2005^{8}$ oficializou o início dos trabalhos. NGAB (2005) relata que as características climáticas, a qualidade dos materiais e o nível econômico e social desse continente são relativamente distintos dos referenciados nos códigos internacionais, justificando a implantação do ACC.

Além dos relatórios, códigos e boletins técnicos já desenvolvidos pelos comitês e grupos de pesquisa (como o ACI, a fib e o ACMC) e em desenvolvimento (como o ACC), diversos projetos relacionados ao tema, advindos de vários países do mundo, tem contribuído na evolução dos estudos da durabilidade e vida útil das estruturas de concreto. Como exemplos, citam-

6. International Committee on Concrete Model Code for Asian.

7. Japan Concrete Institute.

8. Em 2006 e 2007, respectivamente, foram realizados o segundo e o terceiro Simpósio Africano do Concreto em prol ao ACC Code, cujos resultados estão disponíveis no site http://www.acmc-ngo.org/. 
se os projetos DURACRETE (1999), LIFECON (2003), DARTS (2003), DURACON (2004), entre outros.

Com o intuito de obter uma probabilidade aceitável para o projeto de durabilidade de estruturas de concreto armado, conferindo desempenho satisfatório durante a vida útil requerida, o DURACRETE - "Probabilistic Performance Based Durability Design of Concrete Structures" - projeto de pesquisa Europeu, desenvolvido entre 1996-1999, foi um dos pioneiros na área. Nele, os princípios da teoria de confiabilidade, já aplicados no projeto estrutural, foram inseridos para o projeto de durabilidade.

Em virtude da crescente necessidade de manutenção, reparo e modernização de antigas infraestruturas civis da Europa (como pontes, portos, túneis, usina hidrelétricas, plataformas off-shore, assim como edifícios públicos), a Comunidade Europeia, sob o programa de sustentabilidade e crescimento competitivo (1998 - 2002), desenvolveu o projeto LIFECON9 (2003). Tal projeto objetiva desenvolver e validar um modelo Europeu genérico e aberto ${ }^{10}$ para integração e predição dos sistemas de manutenção e de planejamento e gerenciamento do ciclo de vida $\left(\mathrm{LMS}^{11}\right)$ de infraestruturas de concreto que facilite alteraçóes na gestáo e manutençáo de facilities $^{12}$; trabalhe com os princípios do ciclo de vida e inclua aspectos relacionados ao desenvolvimento sustentável, atendendo às exigências humanas (uso, segurança, saúde e conforto), ao desempenho técnico, econômico e ecológico, assim como à aceitação cultural.

O projeto contempla aspectos necessários à classificação quantitativa das cargas de degradação, estimativa da vida útil total e residual, sobretudo devido à ação de íons cloretos, carbonatação e sais de degelo, ao planejamento e gerenciamento de açôes de manutenção e à análise do custo do ciclo de vida de estruturas e infraestruturas de concreto. Esses aspectos são atrelados a modelos matemáticos (probabilísticos e semiprobabilísticos), à teoria de confiabilidade e a fatores socioeconômicos. Para atender o objetivo proposto, o projeto LIFECON contou com a participação da comunidade acadêmica, tecnológica

9. Life Cycle Management of Concrete Infrastructures for Improved Sustainability.

10. O atributo "aberto" open (em inglês) significa que o sistema é genérico (generalizável) e permite que se façam modificaçóes/alteraçóes de acordo com as necessidades dos ativos, organizaçóes e agências.

11. LMS - Life cycle Maintenance and Management planning System.

12. Gestão de facilities é a gestão estratégica de pessoas, espaço, processos de trabalho e investimento dentro de um ambiente organizacional (FERREIRA, 2005, p.14). Ressalta-se que a palavra inglesa facilities não foi traduzida, pois não se encontrou, na língua Portuguesa, um termo que a expressasse adequadamente. 
e construtiva da União Européia, gerando um manual disponibilizado na internet, no qual são descritos os principais processos do sistema proposto, incluindo diferentes análises, aproximaçōes, métodos e soluçôes matemáticas.

Destaca-se ainda o projeto DARTS ${ }^{13}$ - "Durable and Reliable Tunnels Structures" - que objetiva o desenvolvimento de ferramentas práticas para dar suporte pró-ativo ao processo de tomada de decisão da escolha da alternativa ótima. Neste contexto, consideram-se aspectos associados com custos, tipo e processo de construção, manutenção, condiçôes ambientais, qualidades técnicas e segurança ao longo da vida útil de túneis.

Sob coordenação do CYTED ${ }^{14}$ (1998), em 2000 teve início o projeto DURACON $(2004)^{15}$, o qual objetiva: correlacionar a durabilidade de diferentes concretos com as características ambientais reinantes na Ibero América ${ }^{16}$; estimar, de acordo com o clima de cada região, o teor de cloretos necessário para desencadear a corrosáo do aço e propor modelos de previsão de vida útil adequados aos ambientes de estudo. Mediante a exposição de corpos de prova com e sem armadura, em no mínimo duas atmosferas distintas, sendo uma marinha e outra urbana, em cada país Ibero-Americano participante, monitorou-se a evoluçáo da degradação dos concretos ao longo do tempo, no intuito de correlacionar os dados dos ensaios acelerados com os de estruturas reais. Como resultado, tem-se o mapeamento da agressividade do ambiente de exposição da região de estudo.

O Brasil participou desse projeto contando com quatro estaçôes de envelhecimento natural, localizadas em Goiânia (GO), Natal (RN), Rio Grande (RS) e São Paulo (SP). O trabalho publicado por Rincón (2006) apresenta os resultados preliminares do estudo. No país, ainda há o projeto DURAR ${ }^{17}$ (Rede Brasileira de Estaçôes de Envelhecimento Natural), que por meio da criação de uma rede de estaçôes em localidades distintas (Belém, PA; Rio Grande, RS; São Paulo e Pirassununga, SP), objetiva o estudo da influência do clima na degradação de materiais e componentes de construção, dando suporte às atividades de pesquisa e desenvolvimento no país.

13. Informações sobre o projeto no site: http://www.dartsproject.net/.

14. Programa Iberoamericano de Ciencia y Tecnología para el Desarrollo.

15. Influência da ação do meio ambiente na durabilidade do concreto: Projeto DURACON, Brasil.

16. Fazem parte desta regiáo os países: Argentina, Brasil, Chile, Colômbia, Cuba, Espanha, México, Peru, Portugal, Uruguai e Venezuela.

17. Maiores informaçôes no site http://durar.pcc.usp.br/index.htm. 
No Brasil, a Norma de Desempenho (ABNT NBR 15575, 2013), lançada em 2013, constitui-se no principal documento normativo voltado ao desempenho de edificaçóes habitacionais, com vistas à melhoria da qualidade. Objetiva estabelecer uma sistemática de avaliação de tecnologias e sistemas construtivos habitacionais, tendo como base requisitos e critérios de desempenho expressos em normas técnicas brasileiras vigentes. Também leva em conta a durabilidade e a vida útil das estruturas e suas partes, sugerindo a modelagem matemática como ferramenta para as estimativas de vida útil e análise de desempenho, embora não apresente modelos de aplicação prática para tal. No mesmo ano, a Câmara Brasileira da Indústria da Construção (CBIC) lançou um guia orientativo como leitura complementar à norma com o intuito de cooperar com a comunidade da construção civil e promover a difusão da norma de desempenho em todo o país (CBIC, 2015). Também se destaca a revisão da ABNT NBR 6118:2014 (antiga NB 1) que, de forma prescritiva, tenta inserir as questóes de durabilidade e vida útil no projeto de estruturas de concreto.

Destaca-se que os projetos DURACRETE (1999) e LIFECON (2003) sugerem, em seus relatórios, que as consideraçóes de projeto para a durabilidade e as estimativas de vida útil das estruturas de concreto devem derivar de uma abordagem probabilística, destinando, principalmente, a teoria de confiabilidade para esse fim. O projeto DURACON (2004) ainda discorre acerca dos aspectos determinísticos do processo de degradação.

Os conceitos de durabilidade apresentados nas revisóes recentes dos códigos e normas internacionais (ACI, fib e ISO) são fundamentados em modelos matemáticos, os quais buscam descrever os mecanismos de degradação atuantes na estrutura, incorporando conhecimento de várias áreas (multidisciplinar), como a estatística, a ciência e tecnologia dos materiais, a economia, o projeto e a execução. Dados de inspeçóes, manutenção e reparo de estruturas existentes, dados de ensaios acelerados e o conhecimento de especialistas são usados nos modelos para identificar e calibrar os parâmetros críticos de entrada dessas informaçôes, possibilitando a estimativa mais aproximada e coerente da vida útil de estruturas de concreto.

\section{Desempenho, Durabilidade e Vida Útil}

A degradação das edificaçóes ou suas partes e a consequente redução de seu desempenho deve-se especialmente à agressividade do ambiente de exposição 
e ao surgimento de manifestaçóes patológicas (trincas, fissuras, corrosão, entre outras).

O uso incorreto e/ou a baixa qualidade dos materiais de construção, problemas de projeto e de execução e a ausência ou falha nas açôes de manutenção reduzem a qualidade da construção, causando um envelhecimento precoce, com influência direta nos custos de operação, manutenção e reparo. Em estudo realizado no Brasil, Meira e Padaratz (2002) observaram que os investimentos em intervenções de manutenção, em uma estrutura com alto grau de deterioração, podem chegar a aproximadamente $40 \%$ dos custos de execução do componente degradado.

Permanece o desafio de como projetar edificaçóes duráveis, com no mínimo 50 anos de vida útil. Tem ocorrido nos últimos anos um grande número de desabamentos e colapso de estruturas ou de suas partes ${ }^{18,19,20,21}$, por meio dos quais se verifica que a vida útil das construçôes está atingindo valores muito menores do que os previstos em normas (que para a maioria das estruturas é de 50 anos).

Sinistros ocorridos no Brasil, como o acidente no estádio de futebol Fonte $\mathrm{Nova}^{22}$, assim como os supracitados, causaram prejuízos econômicos, sociais e perdas humanas irreparáveis. Essas ocorrências têm chamado a atenção da comunidade da construçáo brasileira para a necessidade de se desenvolver projetos para a durabilidade, de se estabelecer um maior controle do projeto e da execução de novas edificaçóes e da necessidade do constante monitoramento e/ou manutenção das obras já existentes, visando à melhoria da qualidade das construçóes do país e a garantia da vida útil de projeto.

A vida útil é expressa em anos, sendo estabelecida por várias Normas e Códigos do concreto (ver Tabela 1) uma vida útil de projeto (VUP) mínima

18. Desabamento de edifício em reforma, ocorrido em 27 de agosto de 2013, em São Mateus, São Paulo, SP. Dez mortos e 26 feridos.

19. Desabamento de laje, ocorrido em 11 de fevereiro de 2013, em São João da Barra, RJ. Dez feridos e duas vítimas fatais.

20. Desabamento de marquise, ocorrido em 14 de fevereiro de 2013, em Belo Horizonte, MG. Uma vítima fatal.

21. Desabamento de três edifícios, ocorrido em 25 de janeiro de 2012, centro do Rio de Janeiro. Cinco pessoas morreram.

22. Ruptura parcial do anel superior da arquibancada, ocorrida em 25 de novembro de 2007, Estádio Fonte Nova, Salvador, BA, vitimando sete pessoas. 
de 50 anos para a maioria das estruturas e 100 anos para estruturas civis, como obras de infraestrutura, pontes, viadutos, barragens, entre outras.

Tabela 1. Vida útil de projeto (VUP) mínima para várias normas.

\begin{tabular}{|c|c|c|c|c|c|}
\hline \multirow[t]{2}{*}{ Tipo de estrutura } & \multicolumn{5}{|c|}{ Vida útil de projeto (VUP) mínima } \\
\hline & $\begin{array}{l}\text { BS } 7543 \\
(1992)\end{array}$ & $\begin{array}{l}\text { ISO } 2394 \\
(1998)\end{array}$ & $\begin{array}{l}\text { Fib } 34 \\
(2006) \text { e } \\
\text { EN 206-1 } \\
(2007)\end{array}$ & $\begin{array}{l}\text { NBR } 15575 \\
(2013)\end{array}$ & $\begin{array}{l}\text { Fib } 53 \\
(2010)\end{array}$ \\
\hline Temporárias & $\geq 10$ anos & 1 a 5 anos & $\geq 10$ anos & - & - \\
\hline $\begin{array}{l}\text { Partes estruturais } \\
\text { substituíveis (Ex.: } \\
\text { apoios) }\end{array}$ & $\geq 10$ anos & $\geq 25$ anos & 10 a 25 anos & $\begin{array}{c}23 \text { a } 20 \\
\text { anos }\end{array}$ & 25 a 30 anos \\
\hline $\begin{array}{l}\text { Estruturas para } \\
\text { agricultura e } \\
\text { semelhantes }\end{array}$ & - & - & 15 a 30 anos & - & - \\
\hline Estruturas offshore & - & - & - & - & $\geq 35$ anos \\
\hline $\begin{array}{l}\text { Edifícios industriais e } \\
\text { reformas }\end{array}$ & $\geq 30$ anos & - & - & - & - \\
\hline $\begin{array}{l}\text { Edifícios e outras } \\
\text { estruturas comuns }\end{array}$ & - & $\geq 50$ anos & $\geq 50$ anos & 50 anos & $\geq 50$ anos \\
\hline $\begin{array}{l}\text { Edifícios novos e } \\
\text { reformas de edifícios } \\
\text { públicos }\end{array}$ & $\geq 60$ anos & - & - & - & - \\
\hline $\begin{array}{l}\text { Edifícios } \\
\text { monumentais, } \\
\text { pontes e outras } \\
\text { estruturas de } \\
\text { engenharia civil }\end{array}$ & $\geq 120$ anos & $\geq 100$ anos & $\geq 100$ anos & - & $\geq 100$ anos \\
\hline $\begin{array}{l}\text { Edifícios } \\
\text { monumentais }\end{array}$ & - & - & - & - & $\geq 200$ anos \\
\hline
\end{tabular}

A Norma de Desempenho brasileira (NBR 15575, 2013) indica a VUP em três níveis: um Mínimo (M); um Intermediário (I); e, um Superior (S), sendo o primeiro obrigatório (ver representação esquemática na Figura 1). $\mathrm{Na}$ Tabela 2, apresentam-se os valores de VUP, em anos, especificada pela norma brasileira de desempenho para cada sistema da edificação para os níveis mínimo (M) e superior (S). 


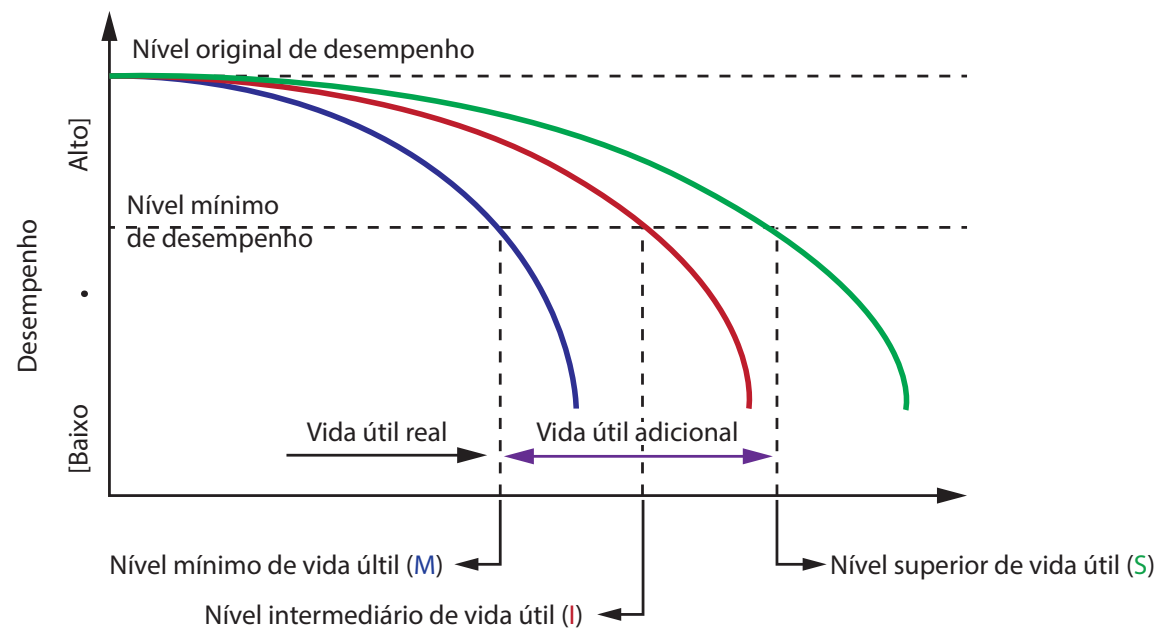

Figura 1. Nível de desempenho $\times$ níveis de vida útil (POSSAN; DEMOLINER, 2013, adaptado de fib 53, 2010).

Tabela 2. vida útil de projeto (VUP)* (em anos) especificada na NBR 15575:2013.

\begin{tabular}{lll}
\hline Sistema & VUP (em anos) & \\
\cline { 2 - 3 } & Mínima (M) & Superior (S) \\
\hline Estrutura & $\geq 50^{* *}$ & $\geq 75$ \\
\hline Pisos Internos & $\geq 13$ & $\geq 20$ \\
\hline Vedação vertical externa & $\geq 40$ & $\geq 60$ \\
\hline Vedação vertical interna & $\geq 20$ & $\geq 30$ \\
\hline Cobertura & $\geq 20$ & $\geq 30$ \\
\hline Hidrossanitário & $\geq 20$ & $\geq 30$
\end{tabular}

* Considerando periodicidade e processos de manutenção segundo a ABNT NBR 5674 e especificados no respectivo Manual de Uso, Operação e Manutenção (Manual do usuário) entregue ao usuário elaborado em atendimento à norma ABNT NBR 14037.

** Segundo a NBR 8681-2004.

No que se refere à modelagem matemática para determinação da VUP, a norma de desempenho não dá indicativos de como conduzi-la, tampouco existem normas ou recomendaçóes técnicas no Brasil para esse fim.

Logo, como conduzir a modelagem matemática para prever vida útil do sistema "estrutura" de uma edificação? Existem modelos de previsão? Eles são de fácil aplicação pelo setor da construção civil? Como garantir que os valores 
de vida útil especificados efetivamente serão atingidos? Tais questionamentos são de extrema relevância e uma discussão sobre as principais questôes são apresentadas na sequência.

\section{Metodologia para a Modelagem e Previsão de Vida Útil de Estruturas de Concreto}

Partindo-se do pressuposto que para prever a vida útil de estruturas de concreto tem-se a necessidade de um modelo matemático representativo do dano, Possan (2010) propóe quatro etapas para se conduzir a modelagem e a previsão de vida útil de estruturas de concreto armado: i) coleta de dados; (ii) modelagem da degradação; (iii) simulação da degradação e (iv) tomada de decisão, conforme fluxograma da Figura 2 (ver também POSSAN, DAL MOLIN e ANDRADE, 2011).

Quando se deseja obter ou melhorar um modelo de degradação, a predição de vida útil pode ser iniciada na etapa 1. Já quando se deseja fazer previsóes com modelos já existentes, o processo inicia-se na etapa 3.

A metodologia pode ser empregada para estimativas de vida útil de estruturas já existentes ou novas estruturas. No primeiro caso, é possível estimar quantos anos são necessários para que a estrutura atinja o estado limite desejado (de durabilidade, serviço ou de segurança). No segundo, fornece subsídios para a seleção da espessura de cobrimento, resistência do concreto, tipo de cimento, relação água-cimento, entre outros fatores que influenciam na vida útil de estruturas de concreto. Nos itens seguintes, as etapas descritas na Figura 2 serão detalhadas. 


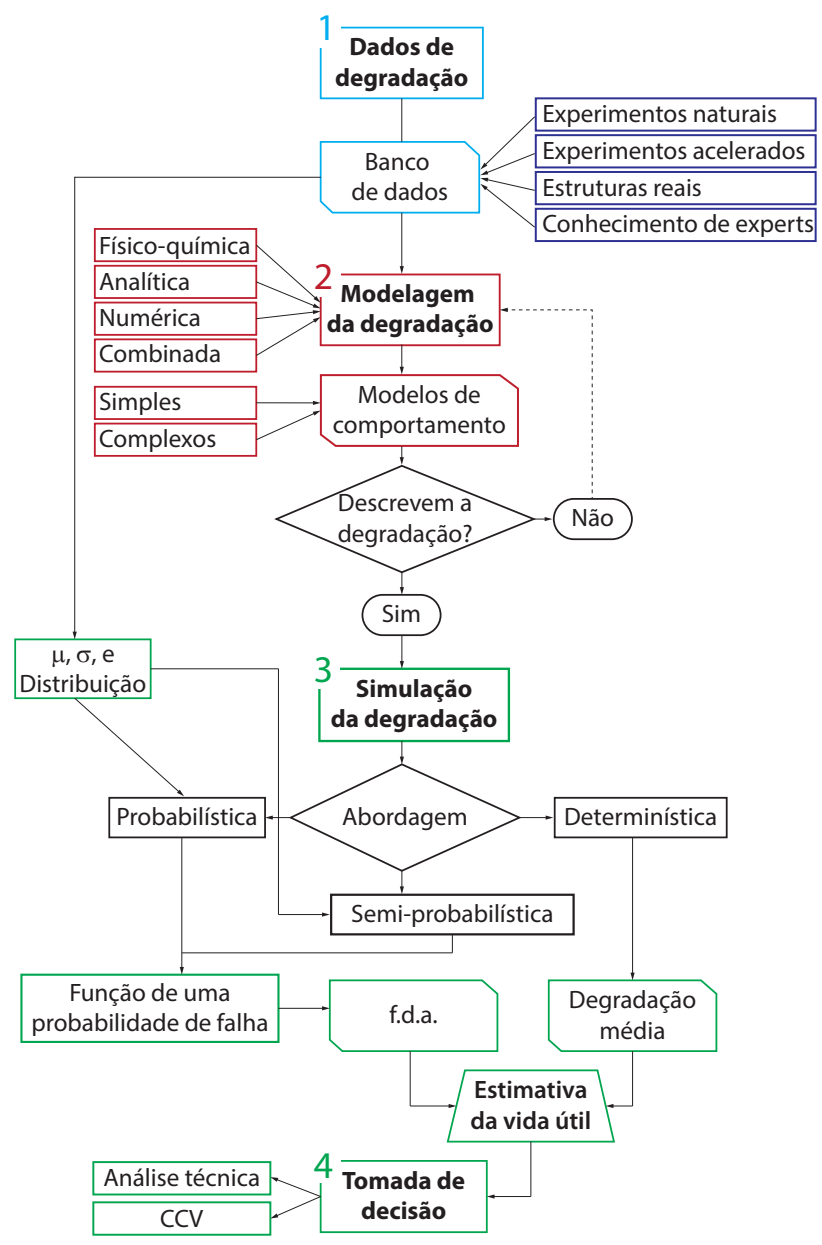

Figura 2. Fluxograma para previsão de vida útil (POSSAN, 2010).

\section{Etapa 1: Dados de Degradação}

A coleta de dados é uma das fases essenciais para os estudos de modelagem e previsão de vida útil, demandando a compilação de informaçôes (objetivas ou subjetivas - ver Tabela 3) acerca dos fatores intervenientes no projeto (como espessura de cobrimento, relação água/aglomerante, resistência), no processo construtivo (nível de controle de qualidade da obra, condiçóes de cura), na durabilidade (tipo e teor de agente agressivo, ambiente de exposição da construção) e nas açôes de operação, manutenção e reparo da edificação. 
Tabela 3. Possíveis fontes de dados de degradação das estruturas de concreto (POSSAN, 2010).

\section{Informação, Dados ou Indicadores}

\begin{tabular}{|c|c|c|}
\hline Tipo & Origem & Observações \\
\hline \multirow[t]{3}{*}{$\frac{0}{\sum_{0}^{\frac{0}{0}}}$} & $\begin{array}{l}\text { Testes acelerados }{ }^{25} \text { de laboratório } \\
\text { de desempenho de materiais, } \\
\text { fornecendo: } \\
\text { - indicadores de desempenho de } \\
\text { ações de manutenção, reparo e } \\
\text { reabilitação; } \\
\text { - indicadores de durabilidade }{ }^{26 ;} ; \\
\text { - indicadores de desempenho das } \\
\text { proteções (pinturas em aço, proteção } \\
\text { anódica, catódica, entre outras); } \\
\text { - agressividade do meio ambiente; } \\
\text { etc. }\end{array}$ & \multirow{2}{*}{$\begin{array}{l}\text { Informações advindas dessas fontes } \\
\text { apresentam elevado potencial de uso. } \\
\text { O ideal é que elas sejam agrupadas em } \\
\text { banco de dados, no intuito de facilitar o } \\
\text { acesso à informação e, consequentemente, } \\
\text { elevar a confiabilidade dos resultados } \\
\text { apresentados. Os bancos de dados } \\
\text { podem ser formados com dados de teses, } \\
\text { dissertações, artigos acadêmicos, estudos } \\
\text { de casos, entre outras fontes confiáveis. } \\
\text { Porém, dados de ensaios acelerados } \\
\text { precisam ser empregados com cautela, } \\
\text { uma vez que para estudos de previsão faz- } \\
\text { se necessária a utilização de um coeficiente } \\
\text { de aceleração }{ }^{27} \text { da degradação. }\end{array}$} \\
\hline & $\begin{array}{l}\text { Investigação in situ fornecendo: } \\
\text { - os indicadores supracitados; } \\
\text { - a velocidade e intensidade } \\
\text { do processo de degradação de } \\
\text { edificações reais. }\end{array}$ & \\
\hline & $\begin{array}{l}\text { Indicadores de desempenho e } \\
\text { eficiência fornecidos pelo fabricante } \\
\text { ou mantenedor do componente, } \\
\text { subsistema e sistema. }\end{array}$ & $\begin{array}{l}\text { Essas informações também são de } \\
\text { utilidade para determinação ou avaliação } \\
\text { dos prazos de garantia. }\end{array}$ \\
\hline 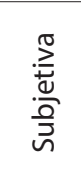 & Experiência de especialistas & $\begin{array}{l}\text { Na carência de dados reais, informações } \\
\text { advindas do conhecimento de experts } \\
\text { podem ser empregadas nos estudos. Para } \\
\text { tal, empregam-se a técnica de grupo focal } \\
\text { e o Método Delphi }{ }^{28} \text {. }\end{array}$ \\
\hline
\end{tabular}

23. Ensaios acelerados são testes comparativos do desempenho de durabilidade de um determinado material, fornecendo resultados em curtos espaços de tempo.

24. Indicador de durabilidade: são propriedades, como porosidade, coeficiente de difusão, teor de $\mathrm{Ca}(\mathrm{OH})_{2}$, entre outras, determinadas por meio de testes de laboratório, que auxiliam na avaliação qualitativa ou quantitativa do potencial de durabilidade de um material (BAROGHEL-BOUNY, 2004).

25. Expressa o número de vezes que o ensaio acelerado representa a degradação natural, sendo relativo aos concretos estudados e às condiçôes de exposição impostas nos dois procedimentos de ensaio (POSSAN, 2004). A determinação desses dados é bastante complexa devido às viabilidades inerentes à degradação.

26. Técnica para a busca de um consenso de opinióes de um determinado grupo de especialistas para um dado tema. O método pressupóe que o julgamento coletivo, quando bem organizado, é melhor que a opiniāo de um só indivíduo. Baseado na consulta estruturada, por meio de um questionário aplicado a um grupo de especialistas, os quais são arguidos até que se obtenha uma convergência das respostas do grupo. 
Cabe destacar a importância de se conhecer o ambiente de exposição da edificação (se marinho, urbano, rural ou industrial) e o grau de agressividade do mesmo (pouco agressivo, agressivo, muito agressivo, entre outros, representado pelo teor de $\mathrm{CO}_{2}{ }^{27}$ do ambiente ou teor de cloretos ou teor de sulfatos) assim como a temperatura e a umidade relativa média do local de construção da edificação. As informaçóes darão subsídio tanto para a modelagem quando para a simulação de vida útil, uma vez que o ambiente de exposição influi diretamente na velocidade e intensidade da degradação da edificação.

\section{Etapa 2: Modelagem da Degradação}

De maneira geral, quando se trata de desenvolvimento de modelos de degradação, há duas fundamentaçóes predominantes: uma empírica e outra fenomenológica ou complexa. A primeira baseia-se na experiência adquirida e em resultados de ensaios já realizados, aplicando, sobretudo, técnicas estatísticas de análise e ajustes de dados na modelagem. Fazem parte desse grupo os modelos de Hamada (1969), Ho e Lewes (1987), Jiang et al. (2000), Andrade (2001), Possan (2010), entre outros. Já a segunda fundamenta-se nas leis gerais da natureza - para o estudo da carbonatação, leis físicas e químicas e deduçóes algébricas. Os modelos provenientes dessas modelagens são criados com base no conhecimento e na análise dos mecanismos e da cinética da degradação, destacando-se, nesse caso, os modelos de Papadakis et al. (1989 e 1991), Saetta e Vitaliani (2004), Thiéry (2005), Hyvert (2009), entre outros.

Os modelos empíricos, também denominados de simplificados, são fundamentados em ajustes de dados de campo ou de laboratório ou baseados na experiência de especialistas e, em geral, possuem solução analítica. Os modelos complexos ou fenomenológicos são baseados em leis físico-químicas, como as leis de conservação de massa de $\mathrm{CO}_{2}$ e de água e, dada a complexidade, exigem soluçóes numéricas (ver quadro comparativo na Tabela 4).

27. Em caso de não ser possível medir o teor de $\mathrm{CO}_{2}$, pode ser empregado o teor médio de $\mathrm{CO}_{2}$ da atmosfera de $350 \mathrm{ppm}$ para ambientes agressivos, $800 \mathrm{ppm}$ para ambientes muito agressivos (grandes cidades, túneis) e $250 \mathrm{ppm}$ para ambientes pouco agressivos (rurais). 
Tabela 4. Modelos empíricos x modelos complexos (POSSAN, 2010).

\begin{tabular}{|c|c|c|}
\hline Fator & Modelos Empíricos & Modelos Complexos \\
\hline Fundamentação & $\begin{array}{l}\text { Experiência de experts, dados } \\
\text { históricos e dados de ensaios } \\
\text { de campo e laboratório }\end{array}$ & $\begin{array}{l}\text { Leis da natureza (físicas e químicas), } \\
\text { formulações algébricas, etc. }\end{array}$ \\
\hline $\begin{array}{l}\text { Parâmetros de } \\
\text { entrada }\end{array}$ & $\begin{array}{l}\text { Em geral simples, de fácil } \\
\text { obtenção }\end{array}$ & $\begin{array}{l}\text { Normalmente exigem a realização de } \\
\text { ensaios para determinação - alguns } \\
\text { são de difícil obtenção }\end{array}$ \\
\hline Precisão & $\begin{array}{l}\text { Erro associado pode ser } \\
\text { elevado }\end{array}$ & Tende a reduzir os erros \\
\hline $\begin{array}{l}\text { Simulação } \\
\text { computacional }\end{array}$ & Simples, em geral, analítica & $\begin{array}{l}\text { Complexa, em geral numérica, } \\
\text { demanda tempos elevados }\end{array}$ \\
\hline $\begin{array}{l}\text { Aplicação } \\
\text { prática }\end{array}$ & Fácil & Difícil \\
\hline Extrapolação & Pode intervir na confiabilidade & $\begin{array}{l}\text { Se bem elaborado, admite } \\
\text { extrapolações }\end{array}$ \\
\hline Generalização & $\begin{array}{l}\text { Aplicável aos intervalos de } \\
\text { informações que deram } \\
\text { origem ao modelo }\end{array}$ & $\begin{array}{l}\text { Aplicável a todas as situações regidas } \\
\text { pelas leis que o compõe }\end{array}$ \\
\hline
\end{tabular}

Em geral, os modelos empíricos são mais fáceis de serem aplicados, entretanto apresentam simplificaçóes, o que pode resultar em resultados menos precisos. Já os complexos consideram um maior número de variáveis de influência no processo de degradação, tendendo a uma maior precisão e generalização, todavia, são mais difíceis de serem aplicados.

Existem diversos modelos na literatura que podem ser empregados para estimativas de vida útil. Entretanto, a grande maioria exige dados de entrada que demandam ensaios prévios laboratoriais (como, por exemplo, coeficiente de difusão de cloretos, tamanho dos cristais de hidróxido de cálcio formado na hidratação do cimento, reserva alcalina, entre outros). Este fato dificulta a utilização de tais modelos pela indústria da construção para a tomada de decisão quando da especificação e utilização do concreto armado. Desta forma, selecionaram-se dois modelos desenvolvidos pelo grupo de pesquisa do NORIE/UFRGS, um para cada mecanismo principal de despassivação das armaduras (cloretos e carbonataçáo), descritos na sequência. 


\section{a) Modelo para Previsão de Vida Útil de Estruturas de Concreto: Iniciação por Cloretos}

Considerando que a corrosão das armaduras é o fenômeno mais incidentes nas estruturas de concreto, ANDRADE (2001) desenvolveu um modelo matemático para representar a penetração de cloretos (que é um dos agentes que podem iniciar o processo corrosivo). Primeiramente foi considerado que tal fenômeno depende basicamente de algumas características relacionadas ao material e ao meio ambiente. Os principais fatores que influenciam no transporte de cloretos estão apresentados na Tabela 5.

Tabela 5. Principais parâmetros que influenciam na penetração de cloretos.

\begin{tabular}{lll}
\hline Características do concreto & Símbolo & Unidade \\
\hline Resistência à compressão (28 dias) & $f_{\mathrm{ck}}$ & $\mathrm{MPa}$ \\
\hline Tipo de cimento & $K_{1}$ & - \\
\hline Tipo de adição & $K_{2}$ & - \\
\hline Quantidade de adição & $A d$ & $\%^{1}$ \\
\hline Características ambientais & & ${ }^{\circ} \mathrm{C}$ \\
\hline Temperatura média ( $\left.{ }^{\circ} \mathrm{C}\right)$ & $T$ & $\%$ \\
\hline Umidade relativa (\%) & $U R$ & $\%^{1}$ \\
\hline Concentração de cloretos (\%) & $\mathrm{Cl}$ & \\
\hline
\end{tabular}

${ }^{1}$ Em relação à massa de cimento.

A penetração de cloretos é proporcional à temperatura, à umidade relativa e à concentração externa de cloretos, sendo inversamente proporcional à resistência à compressão do concreto, ao tipo de cimento e ao tipo e quantidade de adiçôes minerais. Assim, empregando esse princípio e considerando que existe um efeito multiplicativo entre as variáveis básicas, a forma geral do modelo pode ser representada pela Equação 1.

$$
y_{0,4 \%}=K_{0} \cdot \frac{U R^{b_{1}} \cdot T^{b_{2}} \cdot C l^{b_{3}}}{K_{1} \cdot f_{c k}^{b_{4}} \cdot K_{2} \cdot(1+A d)^{b_{5}}} \cdot t^{b_{6}}
$$

onde:

$y_{0,4 \%}=$ posição da concentraçáo crítica de cloretos $\left(C_{c r}\right)$ a partir da superfície do concreto $(\mathrm{mm})$; 
$K_{0}=$ constante geral;

$b_{1}$ a $b_{6}=$ coeficientes das variáveis.

A realização de um trabalho experimental completo para determinar os valores dos coeficientes e das constantes para todas as combinaçóes possíveis demandaria bastante tempo e consumiria muitos recursos para a obtenção dos resultados. Dessa forma, foi realizado um experimento em grupos focais (ou focus groups), em que especialistas foram convidados para responder algumas questôes sobre durabilidade das estruturas. Grupos focais são fóruns que reúnem um pequeno grupo de indivíduos para conversar sobre um tópico de interesse. Basicamente, pode ser considerado como uma entrevista em grupo, embora não com o senso de alternância no qual um pesquisador questiona e os participantes respondem. Ao invés, sua essência consiste na interação entre os indivíduos, baseando-se em tópicos que são promovidos pelo investigador, o qual normalmente assume o papel de moderador da sessão (MORGAN, 1997). O experimento em grupos focais é recomendado para dar orientação em investigaçóes relativas a novos campos de pesquisa, com objetivo de gerar hipóteses baseadas na percepção dos especialistas, avaliar diferentes cenários de pesquisa e fornecer informaçóes adicionais em um estudo em larga escala. Tal ferramenta é empregada em muitos campos exploratórios, como na Engenharia de Produção e nas Ciências Sociais. Na engenharia civil, são raros os trabalhos que empregam essa técnica, destacando-se os trabalhos de Andrade (2001), Bust et al. (2005) e Possan (2010).

Por meio do emprego do experimento em grupos focais obtiveram-se os valores dos coeficientes, cujo modelo final é representado pela Equação 2 (ANDRADE, 2001).

$$
y_{0,4 \%}=7,35 \cdot \frac{U R^{0,7} \cdot T^{0,1} \cdot C l^{0,7}}{K_{1} \cdot f_{c k} \cdot K_{2} \cdot(1+A d)^{0,2}} \cdot \sqrt{t}
$$

onde:

$y_{0,4 \%}=$ posição da concentração crítica de cloretos $\left(C_{\mathrm{cr}}\right)$ a partir da superfície do concreto $(\mathrm{mm})$;

$U R=$ umidade ambiental (\%); 
$T=$ temperatura ambiental $\left({ }^{\circ} \mathrm{C}\right)$;

$C l=$ concentração superficial de cloretos (\%);

$K_{1}=$ fator que varia em função do tipo de cimento (Tabela 6a);

$f_{\mathrm{ck}}=$ resistência à compressão (28 dias) (MPa);

$K_{2}$ = fator que leva em consideração o tipo de adição empregada no concreto, valendo 1,0 quando não se empregam adiçóes (Tabela 6b);

$A d=$ quantidade de adição empregada no concreto (\%); e

$t=$ tempo (anos).

Tabela 6. Coeficientes do modelo em função do tipo de cimento (a) e do tipo de adição (b).

(a)

\begin{tabular}{ll}
\hline $\mathbf{K}_{\mathbf{1}}$ & Tipo de cimento \\
\hline 0,98 & CP II E \\
\hline 1,00 & CP II F \\
\hline 1,05 & CP II Z \\
\hline 1,21 & CP III \\
\hline 1,17 & CP IV \\
\hline 0,95 & CP V ARI \\
\hline
\end{tabular}

(b)

\begin{tabular}{ll}
\hline $\mathbf{K}_{\mathbf{2}}$ & Tipo de adição \\
\hline 1,00 & Sílica ativa \\
\hline 0,97 & Metacaulim \\
\hline 0,76 & $\begin{array}{l}\text { Cinza de casca de } \\
\text { arroz }\end{array}$ \\
\hline
\end{tabular}

Pode ser observado que o valor do coeficiente $b_{6}$ determinado pela análise é igual a 0,5 , valor coerente com a teoria que considera que a penetração de cloretos é proporcional à raiz quadrada do tempo.

Ao se comparar os resultados fornecidos pelo modelo com dados reais obtidos por meio de análises em uma estrutura, verificou-se que o mesmo apresentou níveis de resposta similares à penetração de cloretos medida in situ. Algumas diferenças encontradas podem ser atribuídas a determinados fatores, principalmente às variabilidades existentes nas características do concreto, nas condiçôes ambientais e no processo de extração de amostras e de análise dos resultados. 


\section{b) Modelo para Previsão de Vida Útil de Estruturas de Concreto: Iniciação por Carbonatação}

Seguindo o mesmo procedimento metodológico, Possan (2010) desenvolveu um modelo para prever o avanço da frente de carbonataçáo em concretos, conforme apresentado na equação 3 .

$$
x_{e c}(t)=k_{c} *\left(\frac{20}{f_{c}}\right)^{k_{f c}} *\left(\frac{t}{20}\right)^{0,5} * \exp \left[\left(\frac{k_{a d} * a d^{\frac{3}{2}}}{40+f_{c}}\right)+\left(\frac{k_{c 0_{2}} * c o_{2}^{0,5}}{60+f_{c}}\right)-\left(\frac{k_{U R} *(U R-0,58)^{2}}{100+f_{c}}\right)\right] * k_{c e}
$$

Equação 3

onde:

$x_{e c}(t)=$ profundidade de carbonatação média do concreto, em mm;

$f_{\mathrm{c}}=$ resistência característica à compressão axial do concreto, em MPa;

$k_{\mathrm{c}}=$ fator variável referente ao tipo de cimento empregado (Tabela 7a);

$k_{\mathrm{fc}}=$ fator variável referente à resistência à compressão axial, em função do tipo de cimento utilizado (Tabela 7a);

$t=$ idade do concreto, em anos;

$a d=$ teor de adição pozolânica no concreto, em \% em relação à massa de cimento;

$k_{\mathrm{ad}}=$ fator variável referente às adições pozolânicas do concreto - sílica ativa, metacaulim e cinza de casca de arroz - em função do tipo de cimento utilizado (Tabela 7a);

$U R=$ umidade relativa média, em $\% * 0,01 ;$

$k_{\mathrm{ur}}=$ fator variável referente à umidade relativa, em função do tipo de cimento utilizado (Tabela 7a);

$\mathrm{CO}_{2}=$ teor de $\mathrm{CO}_{2}$ da atmosfera, em \%.

$k_{\mathrm{co} 2}=$ fator variável referente ao teor de $\mathrm{CO}_{2}$ do ambiente em função do tipo de cimento utilizado (Tabela 7a);

$k_{c e}=$ fator variável referente à exposição à chuva em função das condiçôes de exposição da estrutura (Tabela $7 b$ ). 
Tabela 7. coeficientes do modelo em função (a) das características do concreto e das condições ambientais (b) das condições de exposição.

(a)

\begin{tabular}{|c|c|c|c|c|c|}
\hline \multirow[t]{3}{*}{$\begin{array}{l}\text { Tipo de } \\
\text { Cimento }\end{array}$} & \multicolumn{3}{|c|}{ Características do concreto } & \multicolumn{2}{|c|}{$\begin{array}{l}\text { Condições } \\
\text { ambientais }\end{array}$} \\
\hline & Cimento & $f_{c}$ & Adição & $\mathrm{CO}_{2}$ & UR \\
\hline & $k_{c}$ & $\boldsymbol{k}_{\mathrm{fc}}$ & $\boldsymbol{k}_{\mathrm{ad}}$ & $k_{\mathrm{co} 2}$ & $\boldsymbol{k}_{\mathrm{UR}}$ \\
\hline $\mathrm{CPI}$ & 19,80 & 1,70 & 0,24 & 18,00 & 1300 \\
\hline CP IIE & 22,48 & 1,50 & 0,32 & 15,50 & 1300 \\
\hline
\end{tabular}

\begin{tabular}{llllll}
\hline CP II F & 21,68 & 1,50 & 0,24 & 18,00 & 1100 \\
\hline CP II Z & 23,66 & 1,50 & 0,32 & 15,50 & 1300
\end{tabular}

\begin{tabular}{llllll}
\hline CP III & 30,50 & 1,70 & 0,32 & 15,50 & 1300 \\
\hline CP IV & 33,27 & 1,70 & 0,32 & 15,50 & 100
\end{tabular}

\begin{tabular}{llllll}
\hline CP V ARI & 19,80 & 1,70 & 0,24 & 18,00 & 1300 \\
\hline
\end{tabular}

(b)

\section{Condições de \\ exposição da \\ estrutura}

Proteção à $\quad \boldsymbol{k}_{\text {ce }}$

chuva

\begin{tabular}{ll}
\hline $\begin{array}{l}\text { Ambiente } \\
\text { interno }\end{array}$ & 1,30 \\
Protegido da & \\
chuva & \\
\hline Ambiente & 1,00 \\
externo & \\
Protegido da & \\
chuva & \\
\hline $\begin{array}{l}\text { Ambiente } \\
\text { externo }\end{array}$ & 0,65 \\
Desprotegido & \\
da chuva & \\
\hline
\end{tabular}

Para verificar a influência da espessura de cobrimento $\left(d_{c}\right)$ na vida útil assume-se que $x_{e c}(t)=d_{c}$, invertendo-se a equação, na qual o tempo $(t)$ passa a ser a variável de resposta, representando a vida útil da estrutura.

Desta forma, algumas considerações entre diferentes tipos de modelos devem ser realizadas:

- Os modelos teóricos não consideram explicitamente os efeitos de algumas variáveis (umidade relativa, temperatura, tipo de cimento, condições de exposição, entre outras), enquanto os modelos apresentados consideram;

- No caso da penetração de cloretos, a maioria dos modelos teóricos consideram que o tipo de cimento, a resistência à compressão aos 28 dias, o tipo e o teor de adição estão diretamente relacionados com o coeficiente 
de difusão, enquanto o modelo desenvolvido estima o coeficiente de difusão por meio dessas mesmas variáveis;

- O efeito do crescimento da concentração superficial de cloretos é desconsiderado na maioria das formulaçóes, enquanto no modelo desenvolvido para cloretos (Equação 2) tal fenômeno é levado em conta implicitamente na variação do tempo;

- Os modelos resultantes são simples de serem aplicados na atividade de projeto das estruturas, cujos dados de entrada podem ser obtidos facilmente;

- As demais formulações encontradas na literatura envolvem uma maior complexidade matemática no momento da sua resoluçáo (emprego de funções de erro, adoção de hipóteses simplificadas referentes a alguns fenômenos físico-químicos e obtenção de constantes que dependem de ajustes experimentais). Tais dados e/ou ferramentas nem sempre estão à disposição do engenheiro responsável pelo projeto das estruturas de concreto, exigindo a presença de um profissional especializado no momento da previsão da vida útil das estruturas.

\section{Etapa 3: Simulação da Degradação}

A partir de um modelo matemático, faz-se a simulação da degradaçáo (etapa 3), a qual pode ser conduzida por processos probabilísticos ${ }^{28}$, semiprobabilísticos ${ }^{29}$ ou determinístico ${ }^{30}$, independente de como o modelo foi gerado. Nos dois primeiros casos, faz-se necessário o conhecimento da média $(\mu)$, do desvio padrão $(\sigma)$ ou coeficiente de variação $(C V)$ e da distribuição de probabilidade das variáveis aleatórias consideradas, e, em função de uma probabilidade de ocorrência, estima-se a vida útil da estrutura. Nessa abordagem, as incertezas do processo são inseridas na simulação; já na determinística são considerados os valores médios das variáveis de entrada, o que conduz a uma média da degradação da estrutura. Na Figura 3, essas abordagens são representadas graficamente.

28. Considera a distribuição conjunta de todas as variáveis de influência no processo de degradação.

29. Considera, de foram parcial, as variáveis de influência, através de seus valores médios.

30. Não considera a variabilidade dos fatores de influência no processo de degradaçáo. 


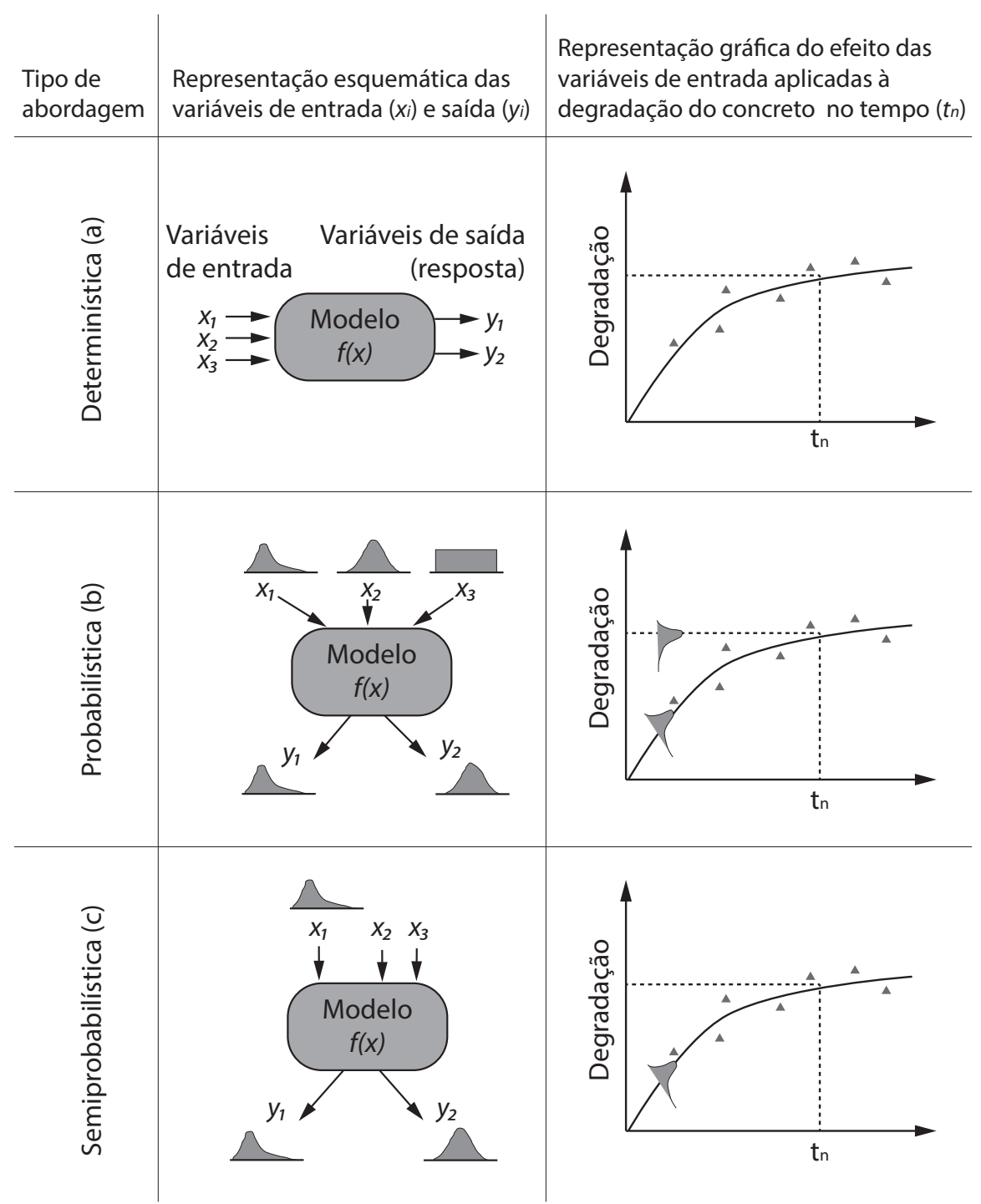

Figura 3. Abordagens para previsão de vida útil (POSSAN, 2010).

$\mathrm{Na}$ estimativa de vida útil por meios determinísticos, a variabilidade do processo de degradação não é considerada. A partir de valores médios das variáveis de entrada, os modelos fornecem como resposta valores médios ${ }^{31} \mathrm{da}$ degradação (profundidade de carbonatação ou de penetração de cloretos) ou do desempenho (espessura de cobrimento, vida útil). Em muitas situações, as informações advindas dos modelos determinísticos são insuficientes,

31. Há casos em que, em vez da média, adota-se um percentil inferior ou superior. 
especialmente quando se deseja avaliar o risco de um projeto alcançar ou não determinado período de vida útil.

Dado que as estimativas de vida útil por meios determinísticos não são associadas a uma probabilidade de ocorrência ou de não ser atingida, Lorenzini (2006) destaca que a vida útil de uma estrutura só pode ser definida em termos probabilísticos, uma vez que esses tipos de dados conseguem inserir nos modelos de comportamento as variabilidades do processo de degradação das estruturas, fornecendo estimativas mais próximas à realidade. Há mais de duas décadas, os métodos probabilisticos para predição de vida útil de estruturas de concreto vêm sendo explorados, destacando os esforços de Siemes et al. (1985), Da Silva (1998), Frangopol (1997), Noortwijk e Frangopol (2004), Andrade (2001), entre outros. Verifica-se que a análise de confiabilidade ${ }^{32}$ é a abordagem probabilística predominante, todavia outros processos estocásticos, como Cadeias de Markov (POSSAN; ANDRADE, 2014), Redes Neurais Artificiais e Lógica Fuzzy, também vêm sendo empregados para esse fim.

Dado que as normas brasileiras não fornecem modelos de previsão para estimativa da vida útil das estruturas de concreto mas, ao mesmo tempo, exigem uma vida útil mínima de projeto de 50 anos, acredita-se ser um passo inicial importante dispor de modelos de simples aplicação que possam simular a degradação, mesmo que de forma determinística, até que se tenha conhecimento suficiente das variabilidades relacionadas às propriedades dos materiais, aos cobrimentos da armadura obtidos em obra, à carga ambiental, entre outros parâmetros, considerando a realidade nacional.

\section{Etapa 4: Tomada de Decisão}

A análise do custo ciclo de vida (CCV) é uma técnica de avaliação de desempenho econômico e se dá por meio de soluçóes de equaçóes diretas e simples, convertendo os custos relevantes do objeto de estudo em valor presente equivalente. Assim, para as estruturas de concreto, a análise do

32. Do ponto de vista de engenharia, confiabilidade é uma medida probabilística da segurança de um sistema - no caso, o sistema seria uma edificação - (ANG e TANG, 1984, p. 01). Em suma, a confiabilidade é uma ferramenta matemática que permite considerar as incertezas do processo de degradação inerentes às estruturas de concreto armado. Para tal, faz uso das suas distribuiçốes de probabilidades, fornecendo a probabilidade de falha da estrutura no tempo. 
CCV é apropriada para a comparação de alternativas de projeto, nas quais os investimentos iniciais são ponderados em relação às açôes de operação, manutenção, reparo e reabilitação para um período de tempo pré-determinado. Nesse caso, a alternativa com o menor custo irá representar a aproximação mais econômica. Em plantas de altos investimentos, as incertezas do processo são consideradas probabilisticamente, por meio da análise de sensibilidade e de riscos, conferindo maior confiabilidade aos resultados.

\section{Aferição dos Modelos de Degradação Propostos por Andrade (2001) e Possan (2010)}

Uma vez selecionados os modelos propostos por Andrade (2001) e Possan (2010) por serem de fácil aplicação para utilização pela indústria da construção civil, e considerando que eles apresentam grande semelhança com os diversos modelos existentes na literatura e com alguns dados de obras e ensaios em ambientes naturais, foram geradas novas informaçóes, a partir de um levantamento das lacunas existentes, que contemplassem os diversos materiais e ambientes existentes no Brasil, por meio da execução de ensaios acelerados e ensaios naturais.

Para tal, foram moldados corpos de prova de concreto e de argamassa em Porto Alegre e remetidos para diversas capitais: Belém, Fortaleza, Goiânia, Vitória e São Paulo. As Tabelas 8 e 9 apresentam o número de corpos de prova confeccionados para cada tratamento (combinação de variáveis independentes) dos concretos e argamassas utilizados, respectivamente.

Tabela 8. Variáveis independentes para execução dos corpos de prova de concreto.

\begin{tabular}{|c|c|c|c|c|}
\hline \multicolumn{5}{|c|}{ Número de corpos de prova de concreto $-10 \times 10 \times 36(\mathrm{~cm})$} \\
\hline \multirow[t]{2}{*}{ Cimento } & \multicolumn{4}{|c|}{ Relação água/cimento } \\
\hline & 0,45 & 0,55 & 0,65 & \\
\hline CPII-F & 21 & 21 & 21 & \\
\hline CPIII & 21 & 21 & 21 & \\
\hline CPIV & 21 & 21 & 21 & \\
\hline CPV & 21 & 21 & 21 & Total \\
\hline Traço & Rico & Interm. & Pobre & $252 \mathrm{CPs}$ \\
\hline
\end{tabular}


Tabela 9. Variáveis independentes para execução dos corpos de prova de argamassa.

\begin{tabular}{lllll}
\hline Número de corpos de prova de argamassa $-7 \times 7 \times 28(\mathrm{~cm})$ \\
\hline Cimento & Traço & & & \\
\cline { 2 - 5 } & Rico & Intermediário & Pobre & \\
\hline CPII-F & 21 & 21 & 21 & \\
\hline CPIII & 21 & 21 & 21 & Total \\
\hline CPIV & 21 & 21 & 21 & 252 CPs \\
\hline CPV & 21 & 21 & 21 & \\
\hline Traço & Rico & Interm. & Pobre & \\
\hline
\end{tabular}

A Figura 4 mostra os corpos de prova embalados para remessa aos locais de exposição. Esse procedimento garantiu que todas as amostras fossem realizadas com os mesmos materiais, mesma metodologia e mesma mão de obra, reduzindo possíveis variabilidades não desejadas. Uma vez entregues ao destino final, os corpos de prova foram expostos, todos com a mesma idade, ao ambiente natural (externo protegido da chuva e externo desprotegido da chuva). Em Porto Alegre, além da exposição ao ambiente natural, um conjunto de corpos de prova foi levado à câmara de carbonatação com concentração de $2 \%$ de $\mathrm{CO}_{2}$, de forma a acelerar o ensaio e correlacionar os resultados com os dos ensaios naturais.

Em idades pré-estabelecidas, foram feitas medidas de profundidade de carbonatação e de penetração de cloretos (somente para Vitória e Fortaleza). 


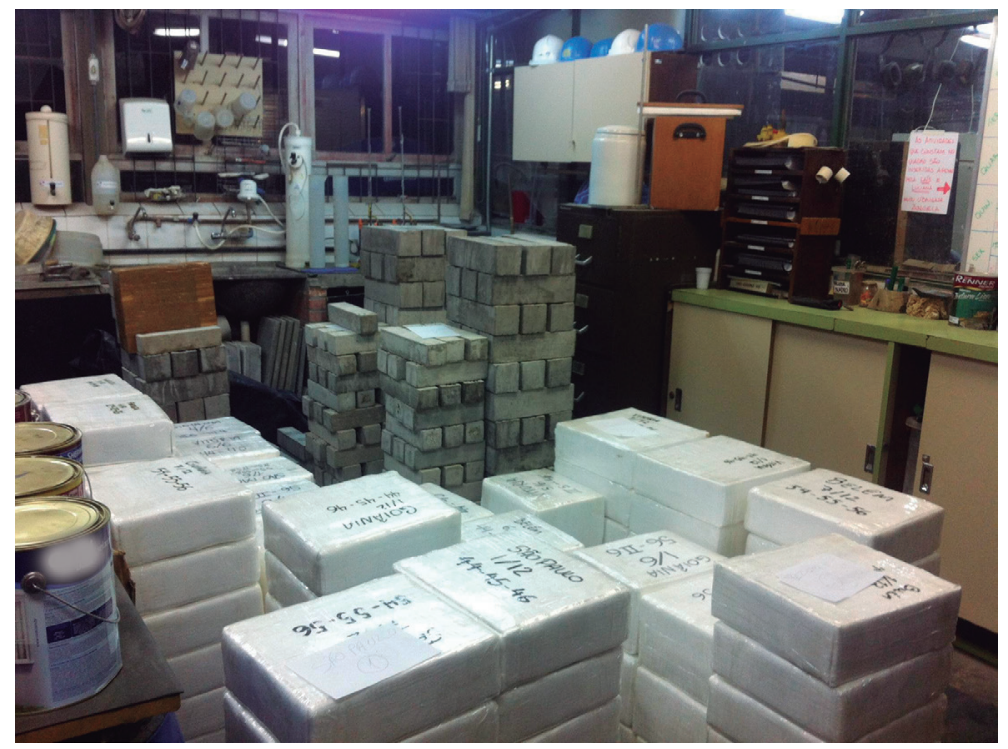

Figura 4. Corpos de prova produzidos em Porto Alegre para remessa aos locais de exposição, com o objetivo de aferir os modelos de previsão da vida útil de estruturas para a realidade brasileira.

De posse dos resultados de todos os ensaios, os dois modelos de previsão (ANDRADE, 2001; POSSAN, 2010) serão aferidos, de forma a garantir que os mesmos possam ser generalizados para o Brasil como um todo.

\section{Previsão de Vida Útil para Sistemas Estruturais em Concreto}

Sabe-se que existem vários agentes que podem levar à degradação de uma estrutura de concreto armado (reação álcali-agregado, ataque químico, entre outros). Todavia, vários levantamentos realizados no Brasil e no exterior mostram que a corrosão das armaduras é a forma de degradação mais frequente nas estruturas.

A corrosão é iniciada por dois agentes: os íons cloreto $\left(\mathrm{Cl}^{-}\right)$, presente nas áreas salinas e industriais, e o $\mathrm{CO}_{2}$, predominantemente presente nos grandes conglomerados urbanos. Sendo assim, há um esforço da comunidade técnicocientífica em se tentar modelar matematicamente a penetração desses agentes através da rede de poros do concreto, visando a prever o tempo entre a colocaçáo da estrutura em serviço e a despassivaçáo da armadura, correspondente ao período de vida útil de projeto (VUP). 
Desta forma, serão apresentados na sequência dois exemplos hipotéticos visando a estimar a vida útil de projeto de uma estrutura, utilizando os modelos propostos nesta pesquisa, para que se possa perceber a influência da variabilidade dos parâmetros de entrada no resultado da simulaçáo.

\subsection{Exemplo para Estrutura Sujeita à Ação de Cloretos}

Neste caso, será apresentado um exemplo de como estimar a vida útil de projeto (VUP) de uma estrutura de concreto armado quando inserida em um ambiente marinho.

\section{Passo: Informações Sobre a Estrutura e o Ambiente de Exposição}

Os dados referentes à estrutura e ao ambiente de exposição são apresentados na Tabela 10. Visando a atingir uma vida útil mínima de projeto (VUP) de 50 anos, serão simulados diversos cenários, variando a resistência do concreto, a espessura de cobrimento, entre outros fatores, para que se possa comparar os efeitos dessas variáveis e de suas variabilidades na vida útil da edificação.

Tabela 10. Dados do ambiente de exposição e da estrutura de concreto.

\begin{tabular}{ll}
\hline Dados necessários para as simulações & \\
\hline Variável/fatores & Média \\
\hline $\mathrm{f}_{\mathrm{C} 28}(\mathrm{MPa})$ & 40 \\
\hline Cobrimento $(\mathrm{mm})$ & 40 \\
\hline Temperatura média $\left({ }^{\circ} \mathrm{C}\right)$ & 25 \\
\hline Umidade relativa $(\%)$ & 70 \\
\hline Tipo de cimento & $\mathrm{CP} \mathrm{IV}$ \\
\hline Teor ambiental de cloretos $(\%)$ & 1,5 \\
\hline
\end{tabular}

\section{Passo: Escolha do Modelo de Degradação e Determinação da Vida Útil}

A simulação determinística é mais simplista, basta inserir as variáveis da Tabela 6 no modelo de degradação devido à ação dos íons cloreto (Equação 2), conforme mostrado na Equação 4. 


$$
t=\left\{\frac{40}{\left[\frac{7,35 \cdot 70^{0,7} \cdot 25^{0,1} \cdot 1,5^{0,7}}{1,17 \cdot 40 \cdot 1 \cdot(1+0)^{0,2}}\right]}\right\}^{2}=50 \text { anos } \quad \text { Equação } 4
$$

Desta forma, verifica-se que para garantir uma vida útil de 50 anos em um ambiente marinho, a estrutura terá que ter uma espessura de cobrimento de projeto igual a $40 \mathrm{~mm}$ e ser construída com um concreto de $40 \mathrm{MPa}$ de resistência à compressão, com o uso do cimento Portland pozolânico (CP IV). Considerando a impossibilidade de alteração das condiçôes ambientais (temperatura, teor de cloretos no ambiente e umidade relativa), a espessura de cobrimento e a resistência do concreto são as duas únicas variáveis que podem ser especificadas no projeto da estrutura, visando à obtenção da vida útil de requerida.

Todavia, sabe-se que em qualquer processo produtivo há a presença de variaçôes dos parâmetros, que está diretamente associada ao controle eà garantia da qualidade de execução. Sendo assim, a consideração dos efeitos dessas variaçôes é de suma importância, pois pode causar alteraçóes significativas na vida útil calculada, conforme será apresentado no item a seguir.

\section{3a Passo: Influência da Variabilidade dos Parâmetros na Penetração de Cloretos}

Pode-se observar nas Tabelas 11 e 12 o impacto de variaçóes da espessura de cobrimento e da resistência do concreto, em separado, na vida útil de projeto, estimada a partir do modelo de degradação devido à ação dos íons cloreto (Equação 2), para estruturas inseridas em ambiente marinho. Para tanto, foram adotados diferentes valores para o desvio-padrão de cada variável, verificando a alteração no valor da VUP (valor médio e desvio-padrão). 
Tabela 11. Impacto das variações da espessura de cobrimento na vida útil de projeto.

\begin{tabular}{lllllll}
\hline $\begin{array}{l}\text { Espessura } \\
\text { de } \\
\begin{array}{l}\text { cobrimento } \\
(\mathbf{m m})\end{array}\end{array}$ & $\begin{array}{l}\text { Desvio- } \\
\text { padrão } \\
(\mathbf{m m})\end{array}$ & $\begin{array}{l}\text { Coeficiente } \\
\text { de variação }\end{array}$ & $\begin{array}{l}\text { Resistência } \\
(\mathbf{M P a})\end{array}$ & $\begin{array}{l}\text { VUP } \\
\text { (anos) }\end{array}$ & $\begin{array}{l}\text { Desvio- } \\
\text { padrão } \\
\text { (anos) }\end{array}$ & $\begin{array}{l}\text { Coeficiente } \\
\text { de variação }\end{array}$ \\
\hline 40 & - & - & 40 & 50 & - & - \\
\hline 40 & 10 & $25 \%$ & 40 & 54 & 28 & $52 \%$ \\
\hline 40 & 20 & $50 \%$ & 40 & 63 & 72 & $114 \%$ \\
\hline 40 & 30 & $75 \%$ & 40 & 79 & 149 & $189 \%$ \\
\hline 40 & 40 & $100 \%$ & 40 & 99 & 271 & $274 \%$ \\
\hline
\end{tabular}

Considerando uma situação de controle de qualidade perfeito durante a execução de uma estrutura, a sua vida útil de projeto seria satisfatória (50 anos) com as especificações relacionadas à espessura de cobrimento $(40 \mathrm{~mm})$ e à resistência do concreto (40 $\mathrm{MPa})$. Todavia, alguns trabalhos desenvolvidos durante este projeto mostram que há uma grande variabilidade tanto na espessura de cobrimento praticada em obra (SILVA, 2012; CAMPOS, 2013; MENNA BARRETO, 2014; MARAN, 2015) quanto na resistência do concreto (MASCOLO, 2012). Sendo assim, o impacto das variações desses parâmetros mostram as grandes alteraçóes no que se refere à previsão da vida útil das estruturas. Por exemplo, para um cobrimento especificado de $40 \mathrm{~mm}$, com desvio-padrão em obra de $10 \mathrm{~mm}$, a estimativa de vida útil seria de $54 \pm$ 28 anos. Já para um desvio-padrão de $20 \mathrm{~mm}$, a estimativa de vida útil seria de $63 \pm 72$ anos.

Considerando a resistência do concreto (Tabela 12), tem-se que coeficientes de variação da ordem de $13 \%$ podem acarretar alterações de até $25 \%$ na previsão da vida útil de projeto. Ou seja: há uma probabilidade significativa de que os 50 anos previstos em projeto não sejam atendidos, caso não sejam criados mecanismos de controle efetivos de execução das obras. 
Tabela 12. Impacto das variações da resistência do concreto na vida útil de projeto.

\begin{tabular}{lllllll}
\hline $\begin{array}{l}\text { Espessura de } \\
\text { cobrimento } \\
(\mathbf{m m})\end{array}$ & $\begin{array}{l}\text { Resistência } \\
\text { (MPa) }\end{array}$ & $\begin{array}{l}\text { Desvio- } \\
\text { padrão } \\
\text { (MPa) }\end{array}$ & $\begin{array}{l}\text { Coeficiente } \\
\text { de variação }\end{array}$ & $\begin{array}{l}\text { VUP } \\
\text { (anos) }\end{array}$ & $\begin{array}{l}\text { Desvio- } \\
\text { padrão } \\
\text { (anos) }\end{array}$ & $\begin{array}{l}\text { Coeficiente } \\
\text { de variação }\end{array}$ \\
\hline 40 & 40 & 2 & $5 \%$ & 51 & 5 & $10 \%$ \\
\hline 40 & 40 & 5 & $13 \%$ & 51 & 13 & $25 \%$ \\
\hline 40 & 40 & 10 & $25 \%$ & 54 & 26 & $48 \%$ \\
\hline 40 & 40 & 15 & $38 \%$ & 58 & 39 & $68 \%$ \\
\hline 40 & 40 & 20 & $50 \%$ & 63 & 54 & $85 \%$ \\
\hline
\end{tabular}

\subsection{Exemplo para Estrutura Sujeita à $A$ ção do $\mathrm{CO}_{2}$}

No exemplo a seguir, será conduzida a previsão de vida útil de uma estrutura de concreto nova, quando inserida em um ambiente urbano, empregando-se a abordagem determinística.

\section{Passo: Informações Sobre a Estrutura e o Ambiente de Exposição}

Visando a atingir uma vida útil mínima de projeto (VUP) de 50 anos, conforme dados referentes à estrutura e ao ambiente de exposição da Tabela 13, serão simulados diversos cenários, variando a resistência do concreto, espessura de cobrimento, entre outros fatores, para que se possa comparar os efeitos destas variáveis e de suas variabilidades na vida útil da edificação.

Tabela 13. Informações do concreto e do ambiente de exposição usadas nas simulações.

\section{Dados necessários para as simulações}

\begin{tabular}{ll}
\hline Variável/fatores & Média \\
\hline $\mathrm{f}_{\mathrm{C} 28}(\mathrm{MPa})$ & $20,30,40$ e 50 \\
\hline Cobrimento $(\mathrm{mm})$ & $20,30,40$ \\
\hline Teor de $\mathrm{CO}_{2}(\%)$ & 0,038 \\
\hline Umidade relativa - UR(\%) & 60 \\
\hline Tipo de cimento & $\mathrm{CP} \mathrm{IV}$ \\
\cline { 2 - 2 } & $\mathrm{CPV}$ ARI \\
\hline Ambiente de exposição & Externo Protegido da chuva (EP) \\
\hline
\end{tabular}




\section{Passo: Escolha do Modelo de Degradação e Determinação da Vida Útil}

A simulação determinística é mais simplista, para um tempo $(\mathrm{t})$ de 50 anos basta substituir as variáveis da Tabela 13 (Cimento $=\mathrm{CP} I V, \mathrm{f}_{\mathrm{c}}=40$ $\mathrm{MPa}, \mathrm{CO}_{2}=0,038 \%$, ambiente de exposição = EP, UR = 60\%) no modelo de degradação devido à ação do $\mathrm{CO}_{2}$ (equação 3), conforme apresentado na Equação 5.

$$
\begin{array}{r}
X_{e c}(t)=33,27 *\left(\frac{20}{40}\right)^{1,7} *\left(\frac{50}{40}\right)^{0,5} \exp \left[\left(\frac{0,32 * 0^{\frac{3}{2}}}{40+40}\right)+\left(\frac{15,5 * 0,038^{0,5}}{60+40}\right)-\left(\frac{100 *(0,60-0,58)^{2}}{100+40}\right)\right] * 1 \\
X_{e c}(50)=16,6 \mathrm{~mm} \quad \text { Equação } 5
\end{array}
$$

Uma estrutura construída com essas características, em 50 anos, apresenta espessura de carbonatação de 16,6 mm. Porém, se a resistência do concreto for reduzida para 30 e $20 \mathrm{MPa}$, a profundidade de carbonatação do concreto passa a ser, respectivamente, de $27,2 \mathrm{~mm}$ e $54,3 \mathrm{~mm}$. Se a espessura de cobrimento da armadura dessa estrutura fosse de $25 \mathrm{~mm}$, apenas no primeiro caso a VUP seria garantida em 50 anos. Isso denota a importância da modelagem matemática para a especificação do projeto visando à durabilidade, com a qual o projetista poderá simular diferentes cenários a fim de escolher a melhor alternativa do ponto de vista técnico e econômico.

\section{3a Passo: Influência da Variabilidade dos Parâmetros na Profundidade de Carbonatação}

O impacto da variação da espessura de cobrimento e da resistência do concreto na vida útil de uma estrutura de concreto sujeita à ação do $\mathrm{CO}_{2}$, considerando o desvio padráo e o coeficiente de variação dos fatores que influenciam na VUP, é apresentado nas Tabelas 14 e 15, respectivamente. As simulaçóes foram conduzidas de forma probabilística, empregando-se o modelo de degradação devido à açáo do $\mathrm{CO}_{2}$ (equação 3) . 
Tabela 14. Impacto das variações da espessura de cobrimento na VUP de estruturas sujeitas à ação do $\mathrm{CO}_{2}$.

\begin{tabular}{|c|c|c|c|c|c|c|}
\hline \multirow[t]{2}{*}{ d (mm) } & \multirow[t]{2}{*}{$\sigma(\mathrm{mm})$} & \multirow[t]{2}{*}{ CV } & \multirow[t]{2}{*}{ fc (MPa) } & \multicolumn{3}{|l|}{ VUP } \\
\hline & & & & $\begin{array}{l}\text { Média } \\
\text { (anos) }\end{array}$ & $\sigma$ (anos) & CV \\
\hline 40 & - & - & 25 & 57,5 & - & - \\
\hline 40 & 10 & $25 \%$ & 25 & 58,9 & 20,6 & $35 \%$ \\
\hline 40 & 20 & $50 \%$ & 25 & 76,7 & 41,2 & $54 \%$ \\
\hline 40 & 30 & $75 \%$ & 25 & 71,4 & 82,4 & $83 \%$ \\
\hline 40 & 40 & $100 \%$ & 25 & 78,7 & 74,1 & $95 \%$ \\
\hline
\end{tabular}

$\mathrm{d}=$ espessura de cobrimento; $\mathrm{fc}=$ resistência à compressão; $\mathrm{CV}=$ coeficiente de variação; $\sigma=$ desvio padrão.

Tabela 15. Impacto das variações da resistência do concreto na VUP de estruturas sujeitas à ação do $\mathrm{CO}_{2}$.

\begin{tabular}{|c|c|c|c|c|c|c|}
\hline \multirow[t]{2}{*}{$\mathrm{d}(\mathrm{mm})$} & \multirow[t]{2}{*}{ fc (MPa) } & \multirow[t]{2}{*}{$\sigma(\mathrm{MPa})$} & \multirow[t]{2}{*}{ CV } & \multicolumn{3}{|l|}{ VUP } \\
\hline & & & & Média (anos) & $\sigma$ (anos) & CV \\
\hline 40 & 25 & 2 & $5 \%$ & 50,1 & 11,1 & $23 \%$ \\
\hline 40 & 25 & 3 & $13 \%$ & 52,3 & 18,3 & $35 \%$ \\
\hline 40 & 25 & 5 & $25 \%$ & 55,9 & 27,7 & $49 \%$ \\
\hline 40 & 25 & 10 & $38 \%$ & 74,1 & 62,1 & $84 \%$ \\
\hline 40 & 25 & 12,5 & $50 \%$ & 86,8 & 83,8 & $97 \%$ \\
\hline
\end{tabular}

$\mathrm{d}=$ espessura de cobrimento; $\mathrm{fc}=$ resistência à compressão; $\mathrm{CV}=$ coeficiente de variação; $\sigma=$ desvio padrão.

Nota-se, na Tabela 14, que coeficientes de variação da ordem de $25 \%$ para a espessura de cobrimento $(\mathrm{d}=40 \pm 10 \mathrm{~mm})$ podem acarretar alteraçóes de até $35 \%$ na previsão da vida útil de projeto, já um coeficiente de variação de $13 \%$ da resistência à compressão do concreto $(\mathrm{fc}=25 \pm 3 \mathrm{MPa}$ ) pode gerar variaçôes de $35 \%$ na vida útil (Tabela 15 ). Nos dois casos, se a variação for negativa (ou seja, se houver redução da espessura do cobrimento ou da resistência à compressão do concreto), a VUP não será atendida (será inferior a 50 anos). Logo, o controle de qualidade da execução das estruturas e da produção do concreto são fundamentais para que a vida útil de projeto seja atendida. 


\section{Variabilidades Existentes no Processo de Produção das Estruturas}

Conforme comentado nas seções precedentes, a estimativa da vida útil de uma estrutura em concreto é incerta devido às variaçóes de geometria, características dos materiais, modo de execução e meio ambiente. Essas variaçóes precisam ser conhecidas para que seja possível prever a vida útil de uma estrutura de forma probabilística. No Brasil, existem poucos dados disponíveis com relação a estas variabilidades. Desta forma, nesta pesquisa buscou-se levantar duas fontes importantes de variabilidade que vão refletir diretamente na vida útil das estruturas (como demonstrado no item 7) e que podem ser minimizadas a partir de procedimentos de controle durante a execução das mesmas: cobrimento de concreto das armaduras e resistência à compressão do concreto.

\subsection{Variabilidade do Cobrimento das Armaduras}

A espessura da camada de cobrimento das armaduras é uma variável que exerce uma influência importante na vida útil das estruturas de concreto. Por náo ser uma variável bem controlada durante o desenvolvimento de uma obra, a alta variabilidade dos valores de cobrimento influencia negativamente na qualidade final das estruturas.

Devido à pouca disponibilidade de estudos brasileiros que estabeleçam as diferenças existentes entre os valores de cobrimento de armadura especificados em projeto e o valor real obtido em obra, antes e após a concretagem, neste projeto foram realizados levantamentos por quatro pesquisadores distintos em obras localizadas em Porto Alegre e em Cuiabá, buscando correlaçóes entre as variabilidades do cobrimento e a qualidade do controle de execução, o tipo de elemento estrutural e o porte das empresas (SILVA, 2012; CAMPOS, 2013; MENNA BARRETO, 2014; MARAN, 2015). As Figuras 5 e 6 e as Tabelas 16 e 17 mostram alguns dos resultados obtidos. 

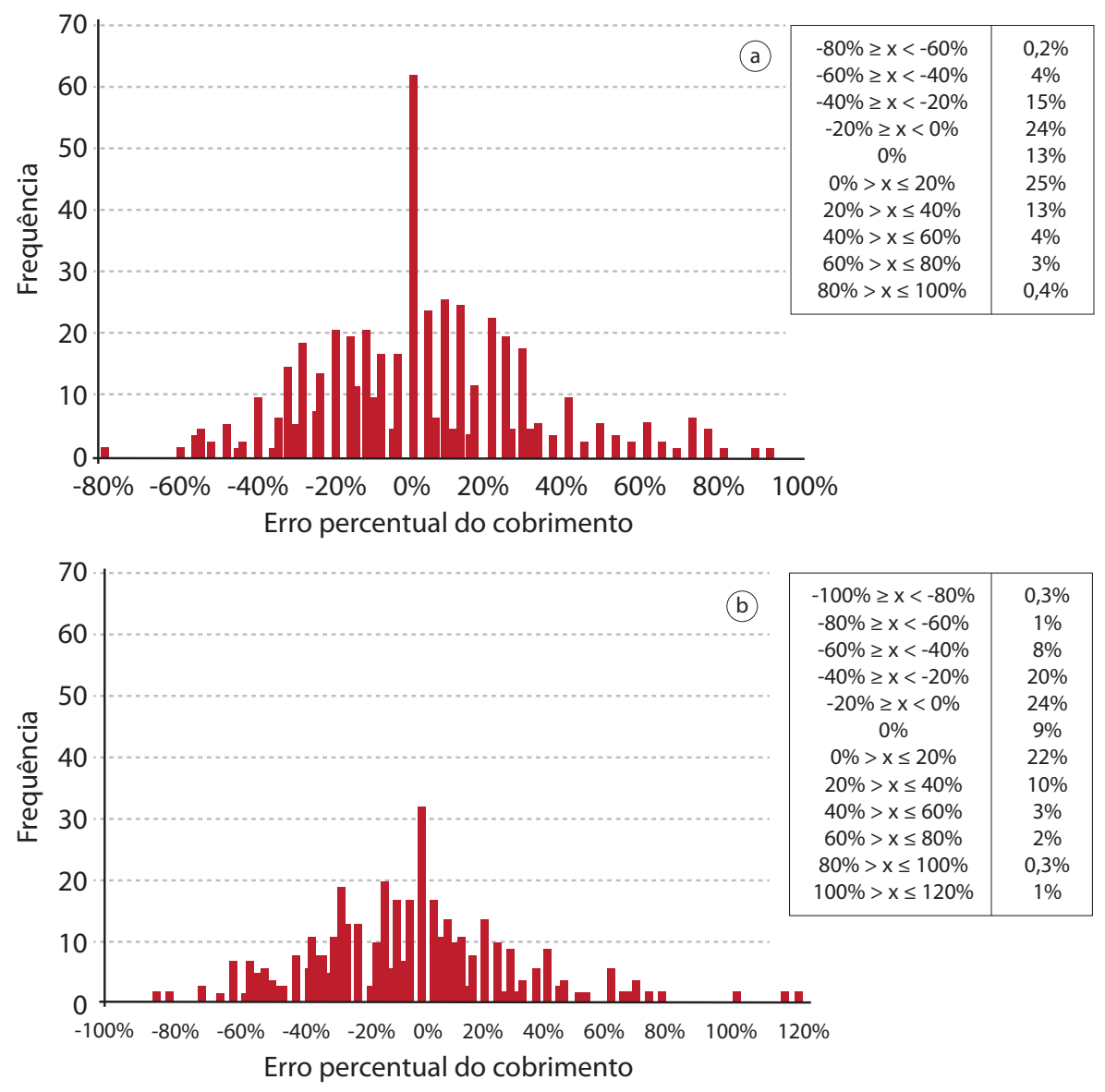

Figura 5. Histograma geral do erro percentual do cobrimento medido em 7 obras em Porto Alegre, antes da concretagem, em relação ao especificado em projeto para (a) 4 obras com elevado controle de qualidade (†odas com certificação de qualidade) e (b) 3 obras com baixo controle de qualidade (SILVA, 2012). 

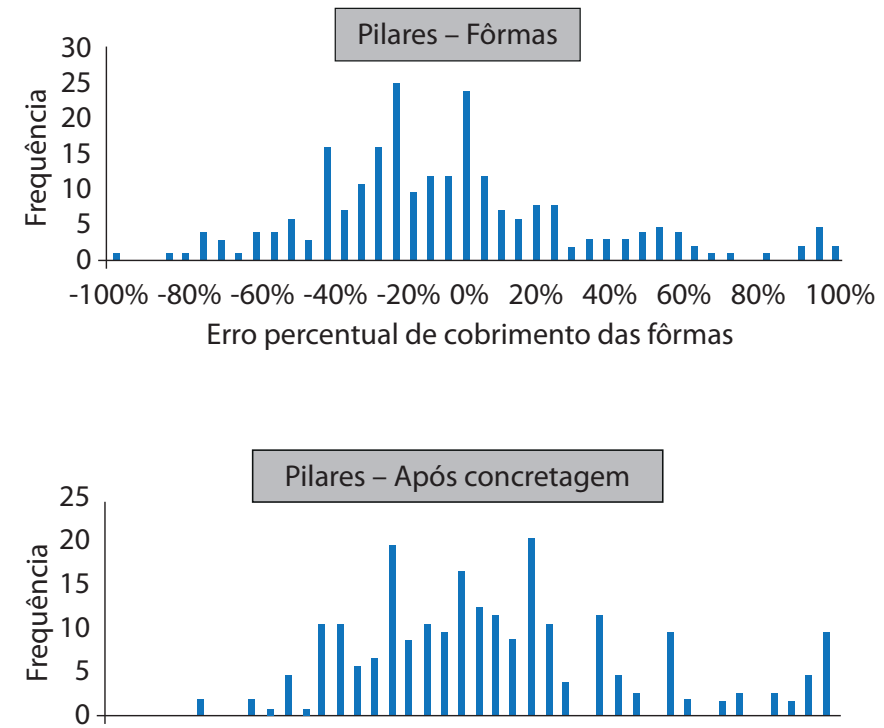

$-100 \%-80 \%-60 \%-40 \%-20 \% \quad 0 \% \quad 20 \% \quad 40 \% \quad 60 \% \quad 80 \% \quad 100 \%$

Erro percentual de cobrimento após concretagem

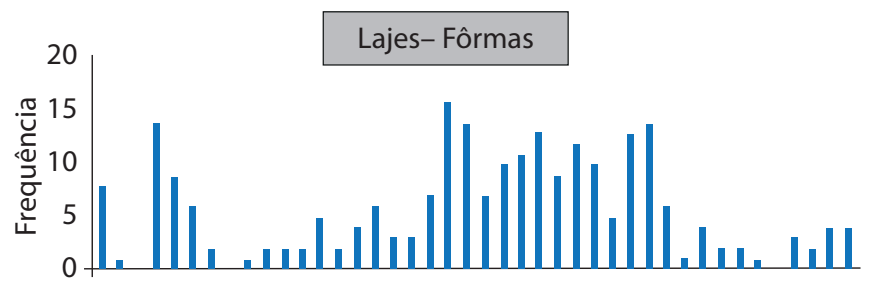

$-100 \%-80 \%-60 \%-40 \%-20 \% \quad 0 \% \quad 20 \% \quad 40 \% \quad 60 \% \quad 80 \% \quad 100 \%$ Erro percentual de cobrimento das fôrmas

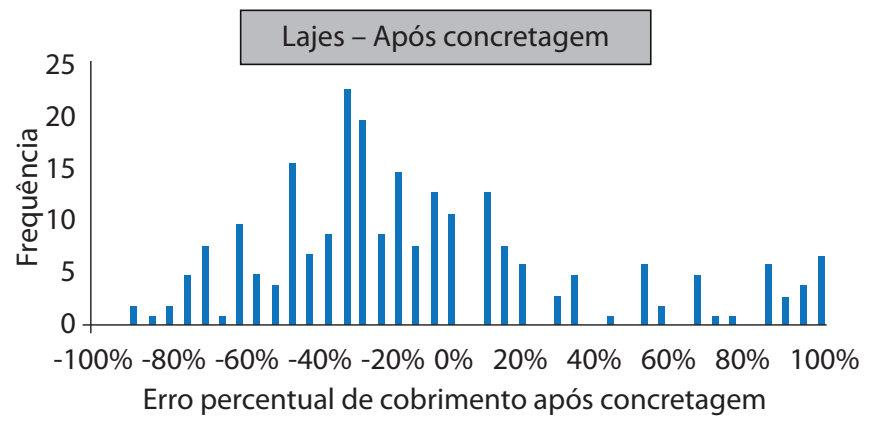

Figura 6. Histogramas gerais do erro percentual do cobrimento medido em 8 obras em Porto Alegre, antes e após a concretagem, em relação ao especificado em projeto (CAMPOS, 2013). 


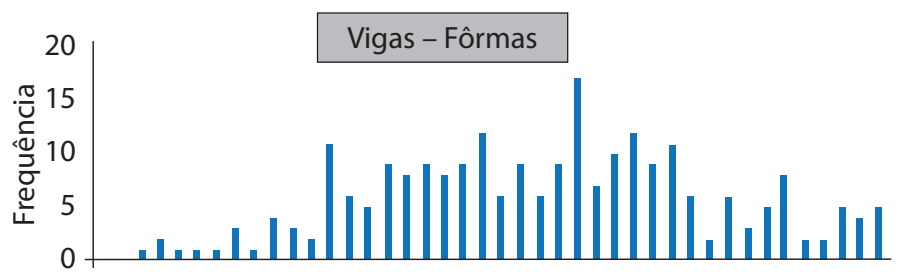

$-100 \%-80 \%-60 \%-40 \%-20 \% \quad 0 \% \quad 20 \% \quad 40 \% \quad 60 \% \quad 80 \% \quad 100 \%$

Erro percentual de cobrimento das fôrmas

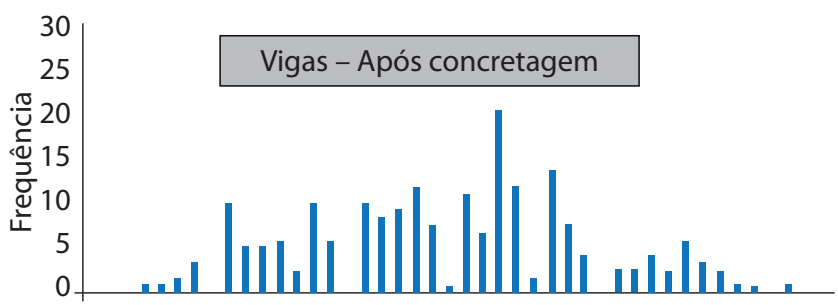

$-100 \%-80 \%-60 \%-40 \%-20 \% \quad 0 \% \quad 20 \% \quad 40 \% \quad 60 \% \quad 80 \% \quad 100 \%$

Erro percentual de cobrimento após concretagem

Figura 6. Continuação.

Tabela 16. Valores mínimos e máximos, em mm, dos cobrimentos executados medidos em obra após concretagem (MENNA BARRETO, 2014).

\begin{tabular}{|c|c|c|c|c|c|c|c|c|c|c|}
\hline \multirow{4}{*}{ Cidade } & \multirow{4}{*}{ Empresa } & \multirow{4}{*}{ Obra } & \multicolumn{8}{|c|}{ Elemento Estrutural } \\
\hline & & & \multirow{2}{*}{\multicolumn{2}{|c|}{ Laje }} & \multicolumn{4}{|l|}{ Viga } & \multirow{2}{*}{\multicolumn{2}{|c|}{ Pilar }} \\
\hline & & & & & \multicolumn{2}{|c|}{ Laterais } & \multicolumn{2}{|c|}{ Fundo } & & \\
\hline & & & $\begin{array}{l}\text { Valor } \\
\text { mín. }\end{array}$ & $\begin{array}{l}\text { Valor } \\
\text { máx. }\end{array}$ & $\begin{array}{l}\text { Valor } \\
\text { mín. }\end{array}$ & $\begin{array}{l}\text { Valor } \\
\text { máx. }\end{array}$ & $\begin{array}{l}\text { Valor } \\
\text { mín. }\end{array}$ & $\begin{array}{l}\text { Valor } \\
\text { máx. }\end{array}$ & $\begin{array}{l}\text { Valor } \\
\text { mín }\end{array}$ & $\begin{array}{l}\text { Valor } \\
\text { Max. }\end{array}$ \\
\hline \multirow{4}{*}{ Cuiabá } & \multirow{3}{*}{ A } & 1 & 4,0 & 23,0 & 16,0 & 49,0 & 11,0 & 28,0 & 5,0 & 63,0 \\
\hline & & 2 & 5,0 & 19,0 & 9,0 & 43,0 & 2,0 & 13,0 & 5,0 & 66,0 \\
\hline & & 3 & 3,0 & 22,0 & 8,0 & 58,0 & 5,0 & 23,0 & 5,0 & 60,0 \\
\hline & B & 4 & 9,0 & 20,0 & 14,0 & 44,0 & 5,0 & 25,0 & 5,0 & 51,0 \\
\hline \multirow{5}{*}{$\begin{array}{l}\text { Porto } \\
\text { Alegre }\end{array}$} & \multirow{3}{*}{ C } & 5 & 5,0 & 17,0 & 3,0 & 42,0 & 3,0 & 17,0 & 4,0 & 60,0 \\
\hline & & 6 & 5,0 & 27,0 & 6,0 & 43,0 & 3,0 & 27,0 & 5,0 & 40,0 \\
\hline & & 7 & 2,0 & 18,0 & 4,0 & 48,0 & 5,0 & 31,0 & 3,0 & 60,0 \\
\hline & \multirow{2}{*}{ D } & 8 & 8,0 & 25,0 & 12,0 & 46,0 & 3,0 & 20,0 & 5,0 & 45,0 \\
\hline & & 9 & 2,0 & 23,0 & 6,0 & 48,0 & 6,0 & 24,0 & 3,0 & 41,0 \\
\hline
\end{tabular}

Medidas do cobrimento em $\mathrm{mm}$. 


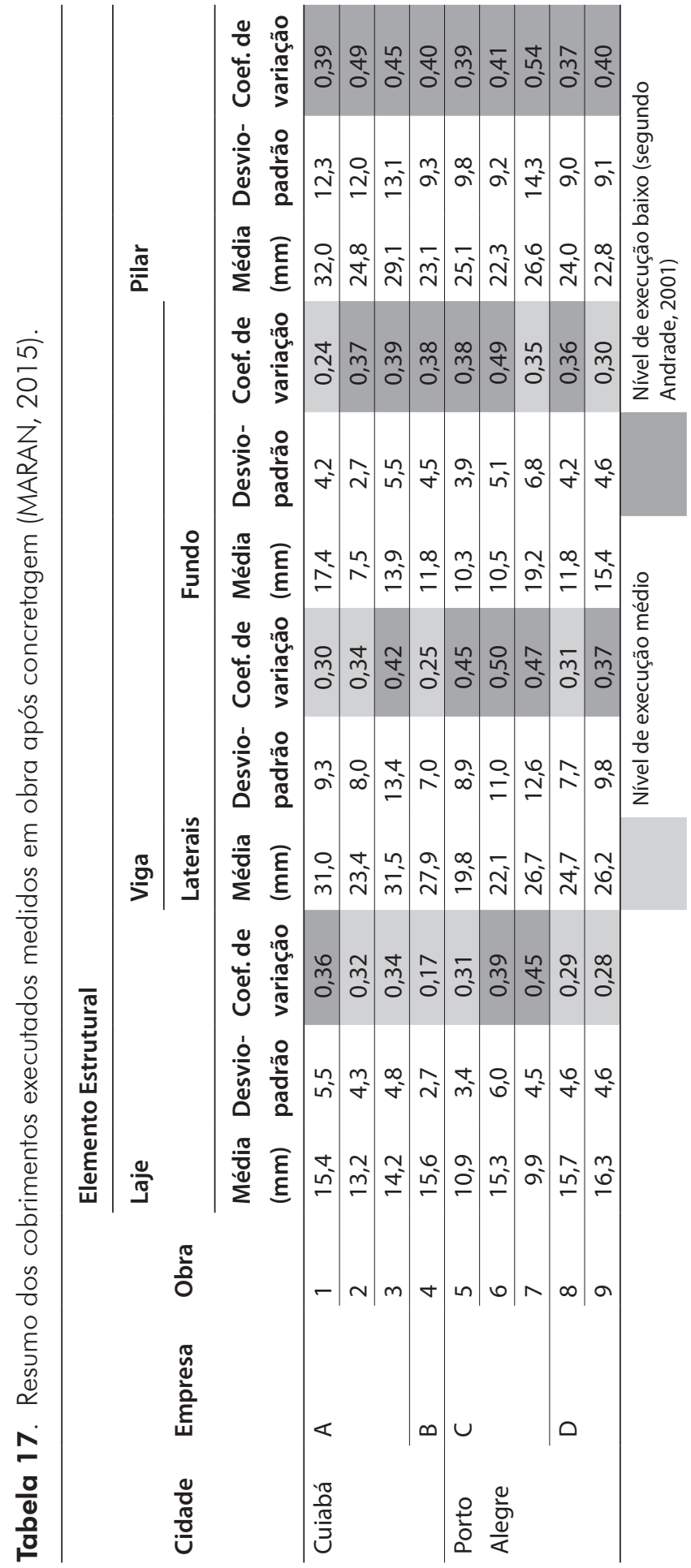


Como se pode observar, todos os dados levantados apontam para uma elevada variabilidade dos cobrimentos executados, independentemente do tipo de elemento estrutural ou do tipo de controle executado.

\subsection{Variabilidade da Resistência do Concreto à Compressão}

Outro parâmetro de relevância que interfere na vida útil de uma estrutura é a especificação e garantia da resistência do concreto à compressão. Para ampliar a base de dados das variaçóes que ocorrem na resistência do concreto em relação à resistência característica especificada, neste projeto realizaram-se coletas de amostras em obras da cidade de Porto Alegre (MASCOLO, 2012). Os principais resultados encontrados são apresentados nas Figuras 7 e 8.

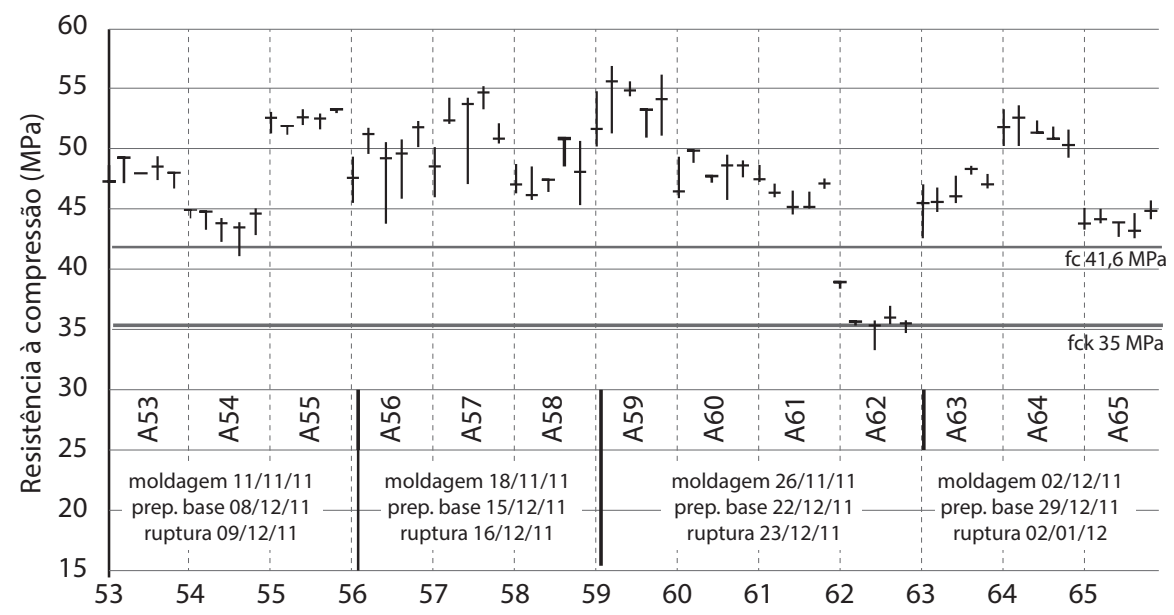

Figura 7. Resistência à compressão dos corpos de prova da obra $A$, onde cada linha de pontos representa o resultado de três corpos de prova que compõem os exemplares de cada lote (MASCOLO, 2012). 


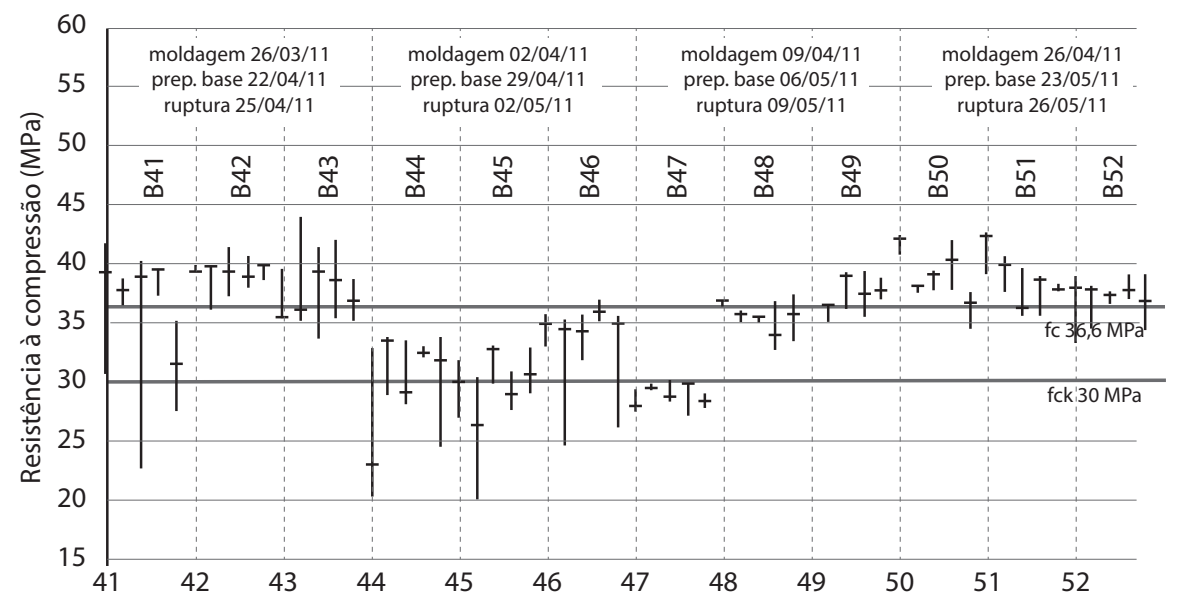

Figura 8. Resistência à compressão dos corpos de prova da obra $\mathrm{B}$, onde cada linha de pontos representa o resultado de três corpos de prova que compõem os exemplares de cada lote (MASCOLO, 2012)

$\mathrm{Na}$ Figura 7, o lote com valor médio menor atingiu 36,7 MPa (A62), enquanto o maior 55,3 $\mathrm{MPa}$ (A59), o que representa uma amplitude de 18,6 $\mathrm{MPa}$. Avaliando os resultados da obra B (Figura 8), percebe-se uma menor amplitude, 11,8 MPa, entre o valor mínimo, 29,5 MPa (B47), e máximo, 41,3 $\mathrm{MPa}$ (B43), de resistência média dos lotes, quando comparados aos resultados da obra $\mathrm{A}$.

Para tentar justificar o motivo das variações encontradas nas resistências dos concretos, buscaram-se dados relativos à variabilidade do cimento Portland que abasteceu o mercado do Rio Grande do Sul no período de 1992 2012 (GIRARDI, 2014). Os resultados encontrados para o cimento CPIV, de elevado consumo no estado, constam nas Figuras 9 a 11. 


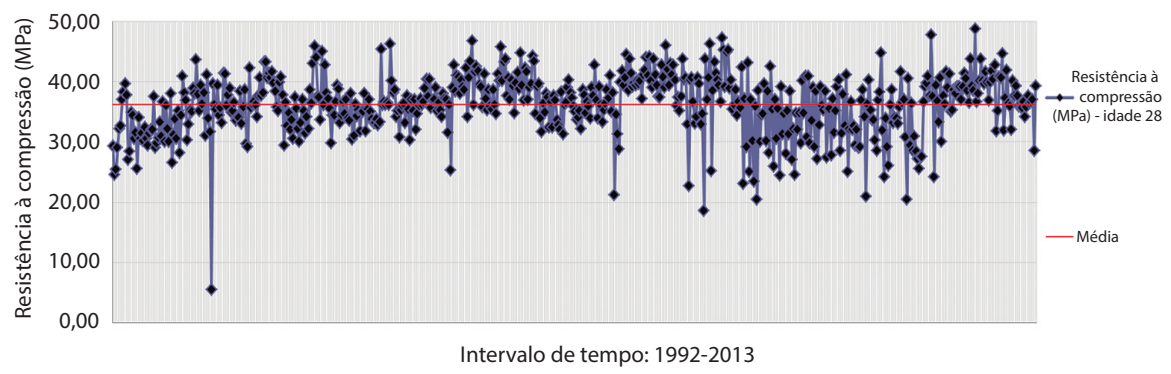

Figura 9. Variação da resistência à compressão do cimento CPIV, marca $A$, ao longo do tempo (GIRARDI, 2014).

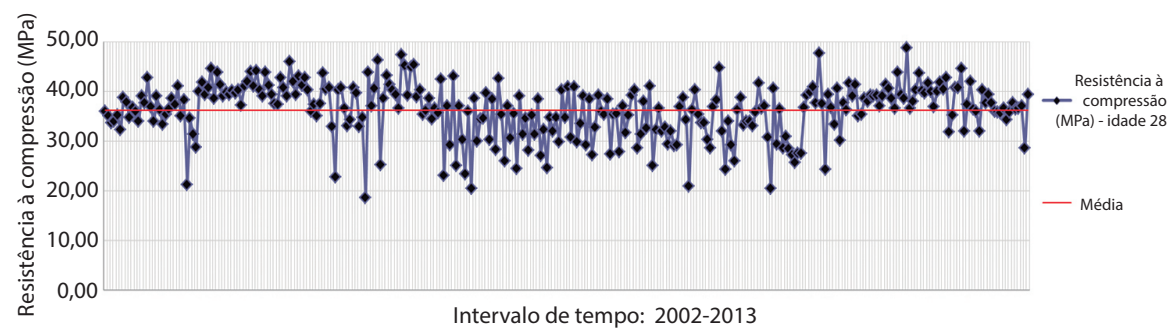

Figura 10. Variação da resistência à compressão do cimento CPIV, marca $B$, ao longo do tempo (GIRARDI, 2014).

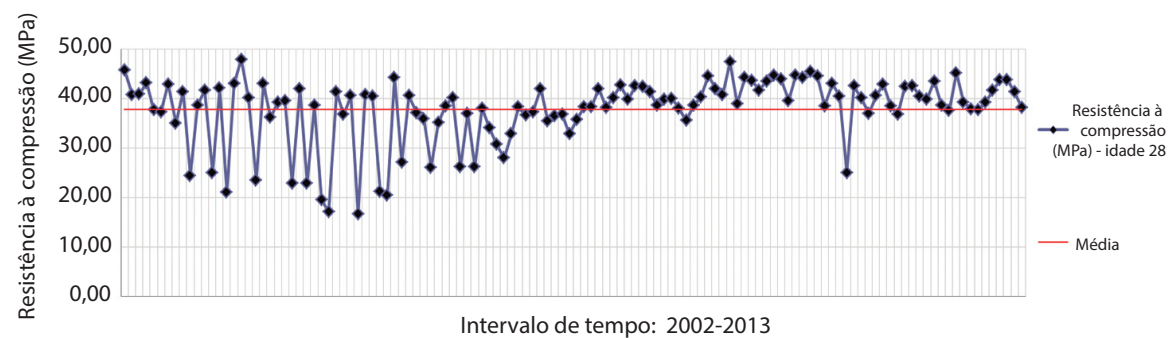

Figura 11. Variação da resistência à compressão do cimento CPIV, marca $C$, ao longo do tempo (GIRARDI, 2014). 
Para o cimento marca A (Figura 9), a média da resistência no período analisado foi de 36,16 MPa, com desvio padrão de 4,89 MPa e coeficiente de variaçáo de $14 \%$. Para o cimento B (Figura 10), a média ficou em 36,21, com desvio de 5,35 MPa e coeficiente de variaçáo de $15 \%$. Esses valores foram de 37,83; 6,70 e 18\% para o cimento C (Figura 11). Nota-se, portanto, que boa parte da variabilidade do concreto pode ser justificada pela variabilidade do cimento.

\section{Considerações Finais}

A previsão de vida útil é um problema complexo, uma vez que as estruturas de concreto, com seus componentes e sistemas, deterioram-se em diferentes taxas, existindo várias incertezas relacionadas às propriedades dos materiais, aos mecanismos de degradação, à resposta estrutural, à carga ambiental e às condiçôes de uso, manutenção e operação, entre outros. Em razão dessas incertezas, os avanços nos estudos de predição de vida útil dessas estruturas estão fortemente relacionados à modelagem adequada da degradação do concreto, tanto determinista quanto probabilisticamente.

Dado que as normas brasileiras não fornecem modelos de previsão para estimativa da vida útil das estruturas de concreto mas, ao mesmo tempo, exigem uma vida útil mínima de projeto de 50 anos, acredita-se ser um passo inicial importante dispor de modelos de simples aplicação que possam simular a degradação, mesmo que de forma determinística, até que se tenha conhecimento suficiente das variabilidades envolvidas para a realidade nacional.

A precisa determinaçáo da vida útil das estruturas de concreto pode ser uma tarefa um tanto difícil de ser realizada. Contudo, desde que se tenha ciência dos vários fatores compreendidos na sua estimativa, não é uma tarefa inexequível, sendo que previsóes que incorporam o acaso, as quais consideram certa probabilidade de algo ocorrer, podem revelar resultados satisfatórios.

Planilhas eletrônicas podem ser facilmente utilizadas para este fim, até mesmo para simulaçóes mais complexas, como as probabilísticas, tal como exemplificada na Figura 12, que apresenta uma interface amigável idealizada como forma de facilitar a utilização dos modelos propostos. 


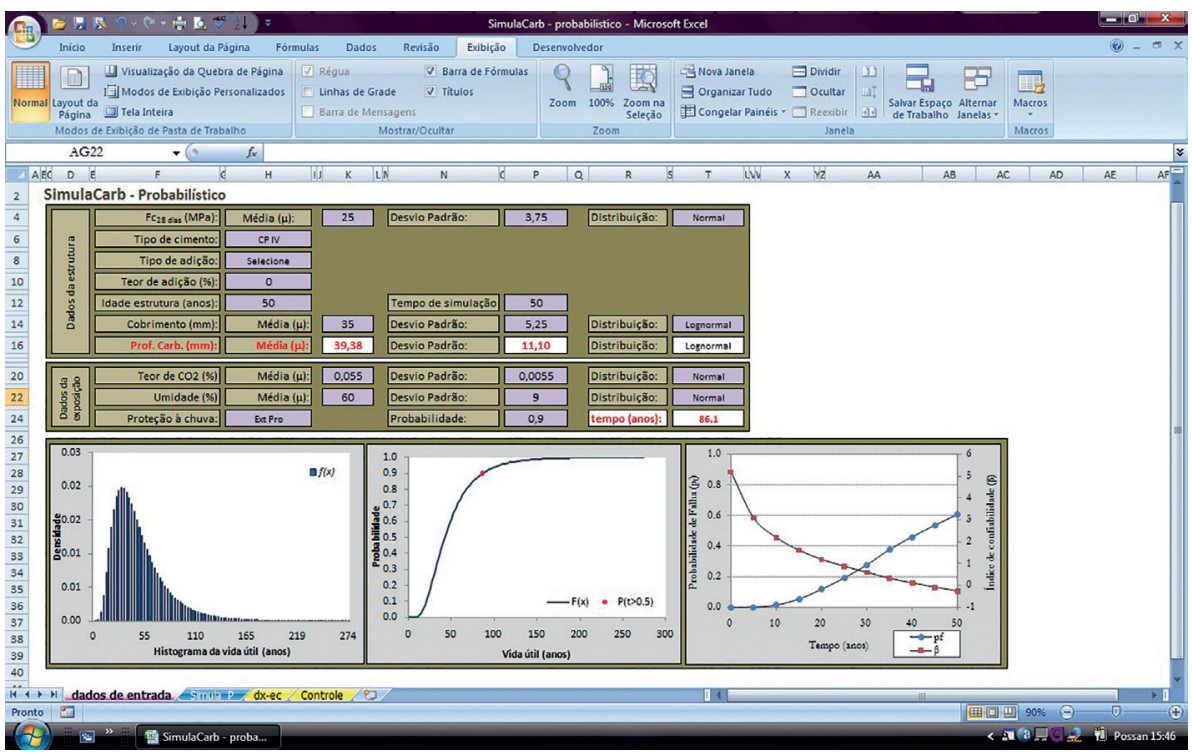

Figura 12. Tela de simulação para a previsão de vida útil de estruturas de concreto onde os dados de entrada são preenchidos nas células lilás e os de saída da simulação aparecem nas células brancas.

\section{Referências Bibliográficas}

AMERICAN CONCRETE INSTITUTE. ACI 201: guide to durable concrete. ACI manual of concrete practice, Detroit, 1992, part 1,39p.

AMERICAN CONCRETE INSTITUTE. ACI 365: service-life prediction: state-of-theart report. Detroit, 2000, 44p.

ANDRADE J. J. O. Análise de danos em estruturas de concreto armado: influência do controle de qualidade de execução através de uma análise probabilística. In: VII Congreso Latinoamericano de Patología de la Construcción y IX Congreso de Control de Calidad en la Construcción, 2003. Mérida, Yucatán, México: Alconpat, 2011. v. 2.

ANDRADE, J. J. O. Contribuição da vida útil das estruturas de concreto armado atacadas pela corrosão de armaduras: iniciação por cloretos. 2001, 256f. Tese (Doutorado em Engenharia) - Curso de Pós-graduação em Engenharia Civil, Universidade Federal do Rio grande do Sul, Porto Alegre, 2001.

ANG, A.; TANG, W. Probability Concepts in Engineering Planning and Design: Decision, Risk and Reliability. v. 2, Ed. John Wiley and Sons, 1984. 562p.

ASIAN CONCRETE MODEL CODE - ACMC. International Committee on Concrete Model Code for Ásia, 2006. Disponível em: <http://www.iccmc.org/index.htm>. Acesso em: 5 mar. 2007. 
ASSOCIAÇÃO BRASILEIRA DE NORMAS TÉCNICAS. NBR 6118 NB1: projeto de estruturas de concreto - procedimento. Rio de Janeiro, 1968, rev. abr, 2014.

ASSOCIAÇÃO BRASILEIRA DE NORMAS TÉCNICAS. NBR 8681: Ações e segurança nas estruturas: Procedimento. Rio de Janeiro, 2004, 2p.

ASSOCIAÇÃO BRASILEIRA DE NORMAS TÉCNICAS. NBR 15577: Agregados Reatividade álcali-agregado. Parte 1: Guia para avaliação da reatividade potencial e medidas preventivas para uso de agregados em concreto. Rio de Janeiro, 2008.

ASSOCIAÇÃO BRASILEIRA DE NORMAS TÉCNICAS. NBR 14037: Diretrizes para elaboração de manuais de uso, operação e manutenção das edificaçóes: Requisitos para elaboração e apresentação dos conteúdos, 2011, 16p.

ASSOCIAÇÃO BRASILEIRA DE NORMAS TÉCNICAS. NBR 10787: Concreto endurecido - Determinação da penetração de água sob pressão. Rio de Janeiro, 2011.

ASSOCIAÇÃO BRASILEIRA DE NORMAS TÉCNICAS. NBR 5674: Manutenção de edificaçôes: Requisitos para o sistema de gestão de manutenção, 2012, 25p.

ASSOCIAÇÃO BRASILEIRA DE NORMAS TÉCNICAS. NBR 9779: Argamassa e concreto endurecidos - Determinação da absorção de água por capilaridade. Rio de Janeiro, 2012.

ASSOCIAÇÃO BRASILEIRA DE NORMAS TÉCNICAS. NBR 15575 - Partes 1-6: Desempenho de Edifícios Habitacionais. Rio de Janeiro, 2013.

ASSOCIAÇÃO BRASILEIRA DE NORMAS TÉCNICAS. NRB 12655: Concreto de cimento Portland - Preparo, controle, recebimento e aceitação - Procedimento. Rio de Janeiro, 2015.

BAROGHEL-BOUNY V. Durability Indicators: A Basic Tool for Performance - Based Evaluation and Prediction of Durability. In: Proceedings of International Seminar on Durability and Lifetime Evaluation of Concrete Structures', Higashi-Hiroshima, September, 2004.

BRITISH STANDARD INSTITUTION. BS 7543: Guide to Durability of Buildings and Building Element, Products and Components. London, 2003.

BUST, A. G.; GIBB, F.; HASLAM, R.A. Manual handling of highwaykerbs: focus group findings. Applied Ergonomics, n. 36, p. 417-425, 2005.

CAMPOS, D. de. Cobrimento de armadura em estruturas de concreto armado: análise comparativa entre valores antes, durante e depois da concretagem. Universidade Federal do Rio Grande do Sul. Porto Alegre, 2013.

CÂMARA BRASILEIRA DA INDÚSTRIA DA CONSTRUÇÃO. Desempenho de edificaçôes habitacionais: guia orientativo para atendimento à norma ABNT NBR 15575/2013. Câmara Brasileira da Indústria da Construção. Fortaleza: Gadioli Cipolla Comunicação, 2013, 308p. Disponível em < http://www.cbic.org.br/arquivos/guia_livro/ Guia_CBIC_Norma_Desempenho_2_edicao.pdf>. Acesso em: 15 jan. 2015. 
COMITE EURO-INTERNATIONAL DU BETON. CEB 183: durable concrete structures. Bulletin d'Information, Suecis, n. 183, may 1992, 112p.

COMITE EURO-INTERNATIONAL DU BETON. CEB 238: new approach to durability design: an example for carbonation induced corrosion. Bulletin d'Information, Suecis, n. 238, may 1997, 138p.

CYTED. Manual de Inspección, Evaluación y Diagnostico de corrosión en estructuras de hormigón armado. Programa Iberoamericano d Ciencia y Tecnología para el Desarrollo. Subprograma XV. Corrosión/Impacto Ambiental sobre Materiales. 2. ed., 1998.

DA SILVA,T. J. Predicción de la Vida Útil de Forjados Unidireccionales de Hormigón Mediante Modelos Matemáticos de Deterioro. 1998. 290 f. Tesis Doctoral. Universidad Politécnica de Catalunya. ETSCCP. Barcelona, 1998

DARTS, Durable And Reliable Tunnel Structures. Research project. Framework, 2003. Disponível em: <www.dartsproject.net>.

DURACON. Influência da ação do meio ambiente na durabilidade do concreto: Projeto Duracon, Brasil. Pesquisador responsável Maryangela Geimba de Lima. Relatório de reunião anual, outubro, 2004.

DURACRETE, General Guidelines for Durability Design and Redesign. The European Union-Brite-EuRam III, Project No. BE 95-1347, "Probabilistic Performance based Durability Design of Concrete Structures”, Report No. T 7-01-1, 1999.

EUROPEAN COMMITTEE FOR STANDARDIZATION - EUROCODE 2. Design of concrete structures: General rules and rules for buildings - BS EN 1992-1-1:2004. British-Adopted European Standard, 23-Dec-2004, 230p.

FÉDÉRATION INTERNATIONALE DU BÉTON. FIB Bulletin 34. Model Code for Service Life Design, February 2006.

FÉDÉRATION INTERNATIONALE DU BÉTON. FIB Bulletin 53. Model Code for Structural Concrete Textbook on behaviour, design and performance, Second edition. Volume 3: Design of durable concrete structures, 2010, p. 390.

FERREIRA, F. P. Gestão de Facilities: estudo exploratório da prática em empresas instaladas na regiáo metropolitana de Porto Alegre. 2005. 151p.

FRANGOPOL, D. M. Life-Cycle Cost Design of Deteriorating Structures. Journal of Structural Engineering, v. 123, n. 10, p. 1390-1401, 1997.

GIRARDI, R. Estudo da variabilidade do cimento Portland que abasteceu o Mercado do Rio Grande do Sul no período de 1992 a 2012. Dissertação (Mestrado em Engenharia) Programa de Pós-Graduação em Engenharia Civil, Universidade Federal do Rio Grande do Sul, Porto Alegre, 2014.

HAMADA, M. Neutralization (carbonation) of concrete and corrosion of reinforcing steel. In: INTERNATIONAL SYMPOSIUM ON THE CHEMISTRY OH CEMENT, 5, 1969. Tokyo. Proceedings... Tokyo, 1969, Part III, v. II/4, p. 343-369. 
HO, D. W. S.; LEWIS, R. K. Carbonation of concrete and its prediction. Cement and Concrete Research, v. 17, p. 489-504, 1987.

HYVERT, N. Application de l'approche probabiliste à la durabilité des produits préfabriqués en béton. Thèse de doctorat, Université Paul Sabatier, Toulouse, 2009.

INTERNATIONAL ORGANIZATION FOR STANDARDZATION. Buildings and constructed assets - Service life planning: General principles. International Organization for Standardization - General principles and framework . ISO 15686: Part 1. jun, 2011, 51p.

INTERNATIONAL ORGANIZATION FOR STANDARDZATION. General Principles on the Design of Structures for Durability. ISO 13823. Geneva: ISO/TC, 2008.

INTERNATIONAL ORGANIZATION FOR STANDARDZATION. General principles on reliability for structures. ISO 2394. Geneva: ISO/TC, 1998.

JIANG, L.; LIN, B.; CAI, Y. A model for predicting carbonation of high-volume fly ash concrete. Cement and Concrete Research, v. 30, p. 699-702, 2000.

LIFECON. Methodology and data for calculation of life cycle costs (LCC) of maintenance and repair methods and works. Deliverable 5.2. Author Minna Kesäläinen. (Project -CT2000-00378, 2003).

LORENZINI, R. V. Avaliação probabilística da deterioração de estruturas em concreto armado. Dissertação. 2006. Curso de Pós-Graduação em Engenharia de Estruturas da Universidade Federal de Minas Gerais, 2006.

MANGAT, P. S. Microestruture, Chloride Diffusion and Reinforcement Corrosion in Blended Cement Paste and Concrete. Cement and Concrete Composites, v. 16, p. 73-81, 1994.

MARAN, A. P. Proposta de distribuição de espaçadores plásticos para garantir o cobrimento especificado em lajes de concreto armado. Dissertação (Mestrado em Engenharia) Programa de Pós-Graduação em Engenharia Civil, Universidade Federal do Rio Grande do Sul, Porto Alegre, 2015.

MASCOLO, R. Concreto usinado: análise da variação da resistência à compressão e de propriedades físicas ao longo da descarga do caminhão betoneira. Dissertação (Mestrado em Engenharia) - Programa de Pós-Graduação em Engenharia Civil, Universidade Federal do Rio Grande do Sul, Porto Alegre, 2012.

MEIRA, G. R.; PADARATZ, I. J. Custos de recuperação e prevenção em estruturas de concreto armado: uma análise comparativa. In: ENCONTRO NACIONAL DE TECNOLOGIA DO AMBIENTE CONSTRUÍDO, IX, 2002, Foz do Iguaçu. Anais... Porto Alegre: 2002, p. 1425-1432.

MEJLBRO, L. The Complete Solution of Fick's Second Law of Diffusion with TimeDependent Diffusion Coefficient and Surface Concentration. In: Durability of Concrete in Saline Environment. Proceedings... P. Sandberg (ed.) Lund, 1996, p. 127-158.

MENNA BARRETO, M. F. F. Avaliação de desempenho de espaçadores plásticos: proposição e avanço de métodos de avaliação. Dissertação (Mestrado em Engenharia Civil). Programa de Pós-Graduação em Engenharia Civil. Universidade Federal do Rio Grande do Sul UFRGS. Porto Alegre, 2014. 
MORGAN, D. L. Focus groups as qualitative research. Qualitative research methods series v. 16. 2 ed. London: Sage Publications, 1997.

NGAB, A. S. The African concrete code (ACC). In: African Concrete Code symposium, 2005. Tripoli, Libya, nov 2005, 16p.

NOORTWIJK, J. M. V.; FRANGOPOL, D. M. Two probabilistic life-cycle maintenance models for deteriorating civil infrastructures. Probabilistic Engineering Mechanics, v. 19, p.345-359, 2004.

PAPADAKIS, V. G.; VAYENAS, C. G.; FARDIS, M. N. Fundamental modeling and experimental investigation of concrete carbonation. ACI Materials Journal, n. 88, p. 363373, 1991a.

PAPADAKIS, V. G.; VAYENAS, C. G.; FARDIS, M. N. Fundamental modeling and experimental investigation of concrete carbonation. ACI Materials Journal, n. 88, p. 363373, $1991 b$.

PAPADAKIS, V. G.; VAYENAS, C. G.;FARDIS, M. N. Reaction engineering approach to the problem of concrete carbonation. Journal of the American Institute of Chemical Engineers, v. 35, n. 10, p.1639-1650, 1989.

POSSAN, E. Modelagem da carbonatação e previsão de vida útil de estruturas de concreto em ambiente urbano. 2010. 263 f. Tese (Doutorado) - Universidade Federal do Rio Grande do Sul, Porto Alegre, 2010.

POSSAN, E. Contribuição ao estudo da carbonatação do concreto com adição de sílica ativa em ambiente natural e acelerado. 2004. Dissertação (Mestrado em Engenharia) Programa de Pós-graduação em Engenharia Civil, Universidade Federal do Rio Grande do Sul, Porto Alegre, 2004

POSSAN, E; ANDRADE, J. J. O. Markov Chains and reliability analysis for reinforced concrete structure service life. Materials Research, v. 17, p. 593-602, 2014.

POSSAN, E., DEMOLINER, C. A. Desempenho, durabilidade e vida útil das edificaçóes: abordagem geral. Revista Técnico-Cientifica CREA-PR. v. 1, 2013.

POSSAN, E.; DAL MOLIN, D. C. C.; ANDRADE, J. J. O. Metodologia para a modelagem e previsão de vida útil de estruturas de concreto. In: XI Congreso Latinoamericano de Patología de la Construcción y el XIII Congreso de Control de Calidad en la Construcción, 2011, Antigua Guatemala. Mérida, Yucatán, México: Alconpat, 2011. v. 1.

RINCÓN, O, T.; DURACON Collaboration. Durability of concrete structures: DURACON, an Iberoamerican project. Preliminary results. Building and Environment, n. 41, 2006 p. 952-962.

SAETTA, A.V.; VITALIANI, R. V. Experimental investigation and numerical modeling of carbonation process in reinforced concrete structures. Part I: Theoretical formulation. Cement and Concrete Research, v. 34, p. 571-579, 2004. 
SIEMES,T.et. al. Durability: A Probabilistic Approach. Durability of Building Materials, n. 3, 1985, p. 101-113.

SILVA, O. S. P. Cobrimento de armadura em estruturas de concreto armado: análise comparativa entre o valor especificado em projeto e o em execuçáo em obras na cidade de Porto Alegre. 2012. Monografia - Escola de Engenharia, Universidade Federal do Rio Grande do Sul, Porto Alegre, 2012.

THIÉRY, M. Modélisation de la carbonatation atmosphérique des bétons: Prise en compte des effets cinétiques et de l'état hydrique. Thèse de doctorat, Ecole Nationale des Ponts et Chaussées, Paris, 2005.

TUUTTI, K. Corrosion of Steel in Concrete. Swedish Cement and Concrete Research Institute. Stockholm, Suecis, 1982. 30p.

UJI, K. et al. Formulation of an Equation for Surface Chloride Content of Concrete due to Permeation of Chloride. In: Corrosion of Reinforcement in Concrete. Ed. C. L. Page. Proceedings... London, p. 285-297, 1990. 